\title{
Modeling the forest dynamics of the Sierra Nevada under climate change using SORTIE-ND
}

\author{
Emily V. Moran ${ }^{1}$ (D) $\cdot$ Nikole Vannest ${ }^{1} \cdot$ Mélaine Aubry-Kientz $^{2}$ \\ Received: 28 January 2021 / Accepted: 10 June 2021 / Published online: 6 September 2021 \\ (C) The Author(s) 2021
}

\begin{abstract}
- Key message Model simulation results suggest that forests in the Sierra Nevada mountains of California will tend to increase in density and basal area in the absence of fire over the next century, and that climate change will favor increases in drought-tolerant species.

- Context Climate change is projected to intensify the natural summer drought period for Mediterranean-climate forests. Such changes may increase tree mortality, change species interactions and composition, and impact ecosystem services.

- Aims To parameterize SORTIE-ND, an individual-based, spatially explicit forest model, for forests in the Sierra Nevada, and to model forest responses to climate change.

- Methods We use 3 downscaled GCM projections (RCP 8.5) to project forest dynamics for 7 sites at different elevations.

- Results Basal area and stem density tended to increase in the absence of fire. Climate change effects differed by species, with more drought-tolerant species such as Jeffrey pine (Pinus jeffreyi A.Murray bis) and black oak (Quercus kelloggii Newb.) exhibiting increases in basal area and/or density.

- Conclusion Increasing forest density may favor carbon sequestration but could increase the risk of high-severity fires. Future analyses should include improved parameterization of reproduction and interactions of disturbance with climate effects.
\end{abstract}

Keywords Individual-based model, Climate change, Coniferous forest, Pinus, Quercus, Abies

\section{Introduction}

Climate change impacts on forests have been a major research focus due to their importance for carbon storage (Oren et al. 2001; Bonan 2008; Earles et al. 2014) and other crucial

\section{Handling Editor: Andreas Bolte}

Contribution of the co-authors Conceptualization: Emily V. Moran; methodology: Emily V. Moran, Nikole Vannest, and Mélaine AubryKientz; formal analysis and investigation: Nikole Vannest, Mélaine Aubry-Kientz; writing - original draft preparation: Emily V. Moran, Nikole Vannest, and Mélaine Aubry-Kientz; writing - review and editing: Emily V. Moran, Nikole Vannest, and Mélaine Aubry-Kientz; funding acquisition: Emily V. Moran; resources: Emily V. Moran; supervision: Emily V. Moran

Emily V. Moran

emoran5@ucmerced.edu

Nikole Vannest

nikolevannest@gmail.com

Mélaine Aubry-Kientz

melaine.aubry.kientz@gmail.com functions (Flint et al. 2013; Goulden and Bales 2014; Grossiord et al. 2014), as well as the concern that long generation times could limit tree responses (Rice and Emery 2003; Aitken and Whitlock 2013). The forests of the Sierra Nevada mountains in California are adapted to a dry summer/wet
1 University of California, Merced, 5200 N. Lake Road, Merced, CA 95343, USA

2 AMAP, Univ Montpellier, CIRAD, CNRS, INRAE, IRD, Montpellier, France 
winter Mediterranean climate. However, climate change is expected to intensify the water cycle, resulting in more extreme drought and precipitation (IPCC 2013; Reidmiller et al. 2018). Recently, the "hot drought" of 2012-2016 (Swain et al. 2014) was followed by extremely wet years in 2017 (Murray and Lohman 2018) and 2019 (CDWR 2019).

Such changes are expected to impact forest demography. "Background" mortality rates of adult trees in the western USA have increased due to temperature-associated increases in aridity (van Mantgem et al. 2009). Extreme droughts can produce mass mortality events (Allen et al. 2010); The 20122016 California drought killed over 100 million trees, with some local mortality rates exceeding $60 \%$ (Fettig et al. 2019). Growth of all age classes and seedling recruitment are affected by climate too. Our recent analysis found that hotter summer temperatures reduced the survival and growth of most species of Sierra Nevada tree seedlings (Moran et al. 2019). Shifts in forest composition have already been observed. A combination of fire suppression and climate change led to increasing forest density, decreasing numbers of large trees, and a greater abundance of shade-tolerant conifers during the twentieth century (Dolanc et al. 2014b; McIntyre et al. 2015). At lower elevations, oaks have become more abundant relative to pines (Dolanc et al. 2014b; McIntyre et al. 2015), and models predict further shifts in from needle-leaf to broadleaf species (Lenihan et al. 2003; Liang et al. 2017).

Forest responses depend on the demographic responses of different species and life stages, and on species interactions. Because of the long timescales involved - both for tree lifecycles and the timelines of projected climate change simulation models are crucial for better understanding forest dynamics in a changing environment. Individual-based forest simulators account for the interaction of each tree with the environment and the other individuals and species on the landscape, bridging the gap between small-scale individual-based studies and landscape studies. No individual-based forest simulator has been previously parameterized for the Sierra Nevada.

SORTIE-ND (http://sortie-nd.org/index.html) was originally developed for broadleaf forests in the Eastern USA (Pacala et al. 1996; Martin et al. 2010), but has since been used for multiple forest types (Uriarte et al. 2009; Bose et al. 2015; Ameztegui et al. 2017). Competitive interactions, based on the sizes of neighboring trees, can be accounted for. SORTIE-ND has accessible source code and a website (http://www.sortie-nd.org) where users can share newly developed functions. This accessibility was the main reason we chose this model for our study; comparisons to other models are discussed in Appendix 1. This paper documents the species-level parameterization of SORTIE-ND; we plan to incorporate individual-level variation and heritability of climate responses in future iterations.
We test the performance of the model by hindcasting the dynamics of three plots at different elevations. Then we project the forest responses to changing climate over the next century for seven plots at different elevations, using downscaled forecasts from the most recent Coupled Model Intercomparison Project (CMIP5) (IPCC 2013). We predicted that:

1. Total basal area will increase over time in most of these scenarios, as suggested by past densification and the positive growth responses of many species to warmer winters (Aubry-Kientz and Moran 2017).

2. Changes in tree density will depend on initial stand structure (many small trees that undergo self-thinning vs. a few larger trees).

3. Species that are found in hotter/drier environments or that show more positive growth or survival response to higher temperatures will tend to increase in abundance and/or basal area in the climate change scenarios relative to the control scenario.

\section{Materials and methods}

\subsection{The simulator}

In SORTIE-ND each tree has a DBH (diameter at $1.4 \mathrm{~m}$ ), species, xy coordinates, and status: seedling, sapling $(<1.4 \mathrm{~m}$ tall, non-reproductive), or adult. Minimum adult DBH was computed with a linear model predicting DBH from age calibrated with Forest Inventory and Analysis (FIA) data (https:// www.fia.fs.fed.us/), and the species' minimum reproductive age (Burns and Honkala 1990). At each time step, trees reproduce, grow, and/or die; behaviors can depend on environmental variables. Values for all parameters and names of SORTIEND behaviors are given in Appendix 1.

\subsection{Forest data}

Tree allometry relationships were calculated from FIA data, using the R package MakeMyForests (https://github.com/davisresearch/MakeMyForests). Demographic data come from 26 long-term forest plots maintained by the US Geological Survey (USGS) in Sequoia and Yosemite National Parks (Aubry-Kientz and Moran 2017; Moran et al. 2019). Data include 10 years of seedling censuses and 17-34 years of adult mortality (annual) and growth ( $\sim 5$ year intervals). Ten species were included in our analyses: white fir (Abies concolor (Gordon \& Glend.) Lindl. ex Hildebr.; ABCO), red fir (Abies magnifica A.Murray bis; ABMA), incense cedar (Calocedrus decurrens (Torr.)Florin; CADE), lodgepole pine (Pinus contorta Bol.; PICO), Jeffrey 
pine (P. jeffreyi A.Murray bis; PIJE), sugar pine (Pinus lambertiana; PILA), western white pine (Pinus monticola Douglas ex D.Don; PIMO), ponderosa pine (Pinus ponderosa Douglas ex Lawson; PIPO), canyon live oak (Quercus chrysolepis; QUCH), and California black oak (Q. kelloggii Newb.; QUKE). The analyses of adult growth (Aubry-Kientz and Moran 2017) and survival and growth of seedlings (Moran et al. 2019) have been published. Plot characteristics and analyses of fecundity and adult mortality are described in Appendix 2 and Appendix 3.

\subsection{Choice of climate variables}

We limited the number of climate variables per behavior to two for simplicity and computational efficiency. For adult growth, the two best climate predictors were January minimum temperature and precipitation (Aubry-Kientz and Moran 2017) and for adult mortality July maximum temperature and precipitation (Appendix 2). For the survival of seedlings $>10 \mathrm{~cm}$ in height, the best-fit model included July maximum temperature and total precipitation anomalies averaged over the current and past year, while for growth the current year July maximum temperature and total snow performed better (Moran et al. 2019). However, projections for snow are highly uncertain because they combine already uncertain precipitation projections with calculations of how much falls as snow and the melt rate. As current year precipitation also predicted seedling growth well, we used this and July maximum temperature for both seedling growth and survival. Table 1 shows the direction of climate effects on seedlings versus trees/sapling growth and survival.

\subsection{Model behaviors}

\subsubsection{Growth}

Annual diameter growth $\left(\Delta D_{j, t}\right)$ for adults and saplings is computed as:

$$
\Delta D_{i, t} \sim N\left(\beta_{0, s}+\beta_{1} D_{i, t}+\beta_{2} \sum_{j=1}^{N_{i, t}} \frac{D_{j, t}}{\text { dist }_{i, j}}+\beta_{3, s} J M n_{t}+\beta_{4, s} P_{t}, \sigma_{g}^{2}\right)
$$

where $i$ indicates individual, $s$ species, and $t$ year; $N_{i, t}$ the total neighbors of $i$ in year $t ; D_{j, t}$ the DBH of neighbor $j$; dist $t_{i, j}$ the distance between $i$ and $j ; J M n_{t}$

the minimum January temperature; and $P_{t}$ the precipitation. The $\beta$ 's are estimated parameters, with $\sigma_{g}^{2}$ representing the error term.

Seedling behaviors in SORTIE-ND are usually based on diameter at $10 \mathrm{~cm}$ height. As our data were recorded by height bin without diameter, we created four size classes: 0 (new seedlings); 1 ( $>2$ years old but $<10 \mathrm{~cm}) ; 2(10-50 \mathrm{~cm})$; and $3(50-140 \mathrm{~cm})$. Transitioning to the next size class is a Bernoulli process: $\operatorname{logit}\left(\theta_{i, t}\right)=\beta_{0, s}+\beta_{1} B A_{t}+\beta_{3} J M x_{t}+\beta_{4} P_{t}$

where $\theta_{i, t}$ is the probability of transitioning; $B A_{t}$ is the total adult tree basal area in a $10-\mathrm{m}$ radius; and $J M x_{t}$ is the maximum July temperature. $\beta_{0, s}$ represents a size-specific intercept for size class $s$. Our model was fitted to seedlings that were $>$ $10 \mathrm{~cm}$ tall. The size-specific parameter for class 1 was therefore based on seedlings that died back. The same parameter was applied to class 0 .

\subsubsection{Mortality}

Adult and sapling mortality is modeled as a Bernoulli process:

$$
\begin{aligned}
\operatorname{logit}\left(\theta_{i, t}\right)= & \beta_{0, s}+\beta_{1, s} D B H_{t}+\beta_{2, s} D B H_{t}^{2}+\beta_{3, s} \sum_{j=1}^{N_{i, t}} \frac{D_{j, t}}{\operatorname{dist}_{i, j}} \\
& +\beta_{4} J M x_{t}+\beta_{5} P_{t}
\end{aligned}
$$

where $\theta_{i, t}$ is the probability of dying (Appendix 2).

For seedlings, survival is also a Bernoulli process:

$\operatorname{logit}\left(\theta_{i, t}\right)=\beta_{0, s}+\beta_{1} B A_{t}+\beta_{4} J M x_{t}+\beta_{5} P_{t}$

where $\theta_{i, t}$ is the probability of surviving. Class 0 seedlings were initially given the size effect estimated for seedlings $<10 \mathrm{~cm}$ (Moran et al. 2019), but this resulted in an unrealistic increase in tree density (A4) because the established seedlings $(>10 \mathrm{~cm}$ ) used to fit the model tend to have much higher survival than younger seedlings. Therefore, the class 0 and 1 size effects were "hand-tuned" (see Appendix 4 for an explanation). The parameters had to be reduced (from -2.57) most for $C$. decurrens and A. concolor, which have very small seeds and first-year seedlings, and the least for $P$. jeffreyi and P. lambertiana, which have large seeds and robust seedlings. All species had a maximum local adult BA beyond which we never observed seedlings. Therefore, if local adult BA exceeds the threshold (Appendix 1), the probability of seedling survival is set to 0 .

\subsubsection{Reproduction}

In order to reduce computation time, we implicitly combine seed dispersal and germination, such that the "seeds" actually represent first-year seedlings. The fecundity and dispersal functions are parameterized based on the distribution of firstyear seedlings relative to adult trees (Appendix 3), and germination probability is set to 1 .

Fecundity is simulated with a zero-inflated Poisson (ZIP) distribution: some individuals produce zero offspring (with probability $p$ ), while others produce offspring according to a Poisson distribution with parameter $\lambda$. Where $z_{j, t}$ is the number of new seedlings from tree $j$ in year $t$ : 
Table. 1

\begin{tabular}{lllllllllll}
\hline & ABCO & ABMA & CADE & PICO & PIJE & PILA & PIMO & PIPO & QUCH & QUKE \\
\hline \multirow{2}{*}{ JulMax } & SS:- & SS:- & SS:- & SS:- & SS:- & SS:- & SS:+ & SS:- & SS:- & SS:- \\
& SG:- & SG:+ & SG:- & SG:+ & SG:+ & SG:- & SG & SG:+ & SG:- & SG:- \\
& AS:+ & AS:+ & AS:+ & AS:- & AS:+ & AS:- & AS:+ & AS:- & AS:+ & AS:+ \\
JanMin & AG:+ & AG:+ & AG:- & AG:- & AG:+ & AG:+ & AG:+ & AG:- & AG:- & AG:+ \\
Precip & SS:- & SS:- & SS:+ & SS:+ & SS:+ & SS:+ & SS:+ & SS:+ & SS:+ & SS:+ \\
& SG:- & SG:- & SG:- & SG:- & SG:- & SG:- & SG:- & SG:- & SG:+ & SG:+ \\
& AS:+ & AS:+ & AS:+ & AS:+ & AS:- & AS:+ & AS:+ & AS:+ & AS:- & AS:- \\
& AG:+ & AG:- & AG:+ & AG:+ & AG:- & AG:- & AG:+ & AG:+ & AG:+ & AG:- \\
\hline
\end{tabular}

$P\left(z_{j, t}=0\right)=p+(1-p) e^{(-\lambda)} 0 \leq p \leq 1$

$P\left(z_{j, t}=k\right)=(1-p) \frac{\left(\lambda^{k} e^{-\lambda}\right)}{k} ! 0 \leq \lambda \leq \infty$

Many of our tree species exhibit masting — locally synchronized mass seed production (Koenig et al. 2015; Gallego Zamorano et al. 2018). We therefore used two ZIP distributions for masting and non-masting years respectively (Appendix 3). The probability of masting is based on time since the last mast: $y=\frac{1}{1+\left(\frac{X}{a}\right)^{b}}$

where $y$ is the probability of masting, $X$ is years since last mast, and $a$ and $b$ are fitted parameters.

We modeled dispersal using a two-dimensional Student's (2Dt) distribution (Clark et al. 1999a):

$$
m_{i, t}=\sum_{j=1}^{J_{g}} A \frac{1}{\pi u\left(1+\frac{d_{i, j}^{2}}{u}\right)^{2}} z_{j, t} \text { where } m_{i, t} \text { is the number of }
$$

first-year seedlings found in quadrat $i$ of area $A$ in year $t ; d_{i, j}$ the distance between $i$ and tree $j ; J$ the total potential parent trees; $z_{j, t}$ the number of first-year seedlings produced by $j$; and $u$ the shape parameter of the 2D-t function. Because first-year seedlings are difficult to identify to species, the dispersal and fecundity model was fit at the genus level (Appendix 3).

\subsection{Hindcasting}

We ran 20 simulations using historical climate sequences for three 1 ha USGS plots - POFLABMA (1999-2014), and BBBPIPO and UPLOG (1997-2013) — obtained from the California Basin Characterization Model (CA BCM) model, which downscales $800-\mathrm{km}$-scale global climate data to $270 \mathrm{~m}$
(Flint et al. 2013a). Initial plot maps used coordinates and 1997 or $1999 \mathrm{DBH}$ of adult trees in these plots replicated 9 times in a 3 $\times 3$ array (Appendix 1, Fig. 7). The buffer "ring" of replicated plots compensates for edge effects. To create a seedling map, we calculated the 1999 density within seedling subplots of classes 2 and 3, which are less affected by year-to-year variation, and replicated this density across the whole plot. We then compared the tree density and basal area for each species in the central square to measured values. We also compared species-level averages for individual growth and mortality. For this, we used only the trees initially present in the plot, so that the youngest trees would not skew the comparison.

\subsection{Simulating climate change responses}

Once the model appeared to be capturing the past behavior, we projected forest dynamics for seven plots: the three hindcasting plots plus four new 0.8 ha plots established in Sequoia National Park in 2015 (Table 2). Annual projected climate sequences for 2006-2099 were downloaded from CA BCM for three global climate models (GCMs) and one emissions pathway: RCP 8.5, a "worst-case scenario" that would be expected to produce the strongest effects. While this pre-Paris Climate Accord pathway may be avoided with the initial Nationally Determined Contributions, warming of $2.5-4{ }^{\circ} \mathrm{C}$ by 2100 (between RCP 4.5 and 6) would still occur (IPCC 2013; Rogelj et al. 2016); several countries, including the USA, had not met those NDCs as of 2020 (Roelfsema et al. 2020). Different GCMs produce different outcomes from RCP 8.5: MIROC represents a relatively hot-dry scenario; CCSM a moderate-warm scenario; and CNRM a relatively warm-wet scenario (Appendix 1; Fig. 8). For each plot, a control climate sequence ("current") was created from historical 1974-2014 sequences randomly sampled for the same number of time steps. We ran ten replicates for each site-scenario combination. 
Table. 2 Plot elevation, basal area (BA) when first recorded, and number of trees + saplings total and by species. * Hindcast plot. SNP, Sequoia National Park; YNP, Yosemite National Park; Burn, most recent prescribed burn

\begin{tabular}{|c|c|c|c|c|c|c|c|}
\hline & BBBPIPO* & SP & SJP & $\mathrm{SJ}$ & UPLOG* & SJM & POFLABMA* \\
\hline Park & SNP & SNP & SNP & SNP & SNP & SNP & YNP \\
\hline Plot size (ha) & 1 & 0.8 & 0.8 & 0.8 & 1 & 0.8 & 1 \\
\hline Elevation (m) & 1609 & 1806 & 2170.5 & 2197.6 & 2210 & 2350 & 2542 \\
\hline Burn & - & Pre-2014 & Pre-2014 & - & - & - & - \\
\hline \multirow{2}{*}{$\begin{array}{l}\text { Initial BA }\left(\mathrm{m}^{2}\right) \\
\text { \# trees }\end{array}$} & 63.82 & 55.52 & 79.53 & 78.15 & 52.46 & 83.55 & 108.28 \\
\hline & 1189 & 455 & 310 & 659 & 416 & 473 & 600 \\
\hline \multirow[t]{2}{*}{ A. concolor $(\mathrm{BA}, \#)$} & 8.56 & 24.56 & 57.8 & 43.43 & 42.86 & 20.1 & - \\
\hline & 147 & 149 & 226 & 469 & 366 & 116 & \\
\hline \multirow[t]{2}{*}{ A. magnifica (BA, \#) } & - & - & 2.25 & 34.52 & 0.002 & 58.59 & 105.1 \\
\hline & & & 8 & 179 & 1 & 319 & 565 \\
\hline \multirow[t]{2}{*}{ C. decurrens (BA, \#) } & 27.54 & 0.41 & 4.58 & - & 0.96 & - & - \\
\hline & 630 & 5 & 32 & & 14 & & \\
\hline \multirow[t]{2}{*}{ P. contorta $(\mathrm{BA}, \#)$} & - & - & - & - & - & 1.86 & 3.18 \\
\hline & & & & & & 14 & 35 \\
\hline \multirow[t]{2}{*}{ P. jeffreyi (BA, \#) } & - & - & 7.1 & 0.04 & 0.56 & - & - \\
\hline & & & 30 & 4 & 5 & & \\
\hline \multirow[t]{2}{*}{ P. lambertiana (BA,\#) } & 1.6 & 6.13 & 3.73 & 0.16 & 8.06 & - & - \\
\hline & 65 & 54 & 7 & 7 & 28 & & \\
\hline \multirow[t]{2}{*}{ P. monticola (BA, \#) } & - & - & - & - & - & 3 & - \\
\hline & & & & & & 24 & \\
\hline \multirow[t]{2}{*}{ P. ponderosa (BA, \#) } & 11.31 & 15.0 & 4.07 & - & - & - & - \\
\hline & 31 & 123 & 7 & & & & \\
\hline \multirow[t]{2}{*}{ Q. chrysolepis (BA,\#) } & 0.04 & 0.61 & - & - & - & - & - \\
\hline & 40 & 24 & & & & & \\
\hline \multirow[t]{2}{*}{ Q. kelloggii (BA, \#) } & 14.69 & 8.8 & - & - & 0.02 & - & - \\
\hline & 276 & 100 & & & 2 & & \\
\hline
\end{tabular}

\section{Results}

\subsection{Hindcasting}

In nearly all cases, the observed mean species-level adult growth or mortality was within the $95 \%$ CI for the simulations and vice versa (Table 3). Where there were exceptions, the simulated mean was within the observed range, but the observed mean was higher than the simulated range. Measured total BA and density fell within or close to the $95 \%$ CI of 20 model runs for most species in most plots. However, A. concolor BA and density were somewhat overestimated in UPLOG, and $C$. decurrens BA in BBBPIPO and A. magnifica density in POFLABMA were underestimated (Fig. 1).

\subsection{Climate change responses}

Initial tree densities across plots ranged from 387.5 to 1189 trees/ha and total BA from 52.46 to $108.28 \mathrm{~m}^{2} /$ ha. There was no correlation between initial tree density and initial BA, and while the lowest elevation plot (BBBPIPO) had an unusually high tree density, there was otherwise no relationship between tree density and elevation. There was, however, a trend toward higher initial tree $\mathrm{BA}$ at higher elevations $(\mathrm{p}=0.17$, adjusted $\mathrm{R}^{2}=0.20$; Appendix 5).

Total tree BA and stem density increased over the 93year simulations in all sites except the very dense lowest elevation site, where stem density decreased by about $20 \%$ in all scenarios (Figs. $2 \& 3$ and Appendix 5). Density increases in the other sites ranged from 41.8 to $527.6 \%$ and tended to be related negatively to initial density and positively to elevation, though this was not statistically significant (Appendix 5). Basal area increases ranged from 13.2 to $62.7 \%$ and also tended to be positively related to elevation (Appendix 5). The "warm-wet" scenario $(\mathrm{CNRM})$ resulted in the greatest BA increase and the lowest drop in density at BBBPIPO, as well as the highest increase in BA and density at SP. Response to climate scenarios varied substantially by species. Pinus monticola, $P$. concolor, and $Q$. chrysolepis are omitted from the following species-level discussion due to low abundance. 
Table. 3 Average individual observed and simulated growth and mortality rates over 16 years, $95 \%$ confidence interval in brackets

\begin{tabular}{|c|c|c|c|c|}
\hline & $\begin{array}{l}\text { Observed mean annual } \\
\text { growth }(\mathrm{cm})\end{array}$ & $\begin{array}{l}\text { Simulated mean annual } \\
\text { growth }(\mathrm{cm})\end{array}$ & $\begin{array}{l}\text { Observed mean annual } \\
\text { mortality }(\%)\end{array}$ & $\begin{array}{l}\text { Simulated mean annual } \\
\text { mortality }(\%)\end{array}$ \\
\hline \multicolumn{5}{|l|}{ BBBPIPO } \\
\hline A. concolor & $1.842[0.17-4.63]$ & $0.817[0.41-1.42]$ & $0.851[0-2.82]$ & 1.118 [0-2.88] \\
\hline C. decurrens & $1.119[0.1-2.8]$ & $0.541[0.15-1.05]$ & $1.276[0.33-4.05]$ & $0.796[0.17-1.53]$ \\
\hline P. lambertiana & $1.645[0.2-4.7]$ & $0.754[0.41-1.24]$ & $2.072[0-5.54]$ & $3.03[0-8.1]$ \\
\hline P. ponderosa & $1.887[0.22-4.27]$ & $0.956[0.05-2.14]$ & $1.79[0-10.06]$ & $1.379[0-6.79]$ \\
\hline Q. chrysolepis & $0.6[0.1-2.85]$ & $0.443[0-8.39]$ & $1.029[0-5.37]$ & $0.947[0-5]$ \\
\hline Q. kelloggii & $0.925[0.1-2.1]$ & $0.607[0.6-1.36]$ & $1.296[0.15-3.23]$ & $1.027[0-2.34]$ \\
\hline \multicolumn{5}{|l|}{ UPLOG } \\
\hline A. concolor & $1.618[0.2-4]$ & $1.325[0.87-2.15]$ & $0.738[0.3-1.56]$ & $0.922[0-1.94]$ \\
\hline C. decurrens & $0.943[0.1-1.94]$ & $1.064[0.71-1.7]$ & 0 & $0.86[0-8.03]$ \\
\hline P. lambertiana & $1.947[0.5-4.27]$ & $1.328[0.84-2.35]$ & $1.462[0-4.87]$ & $1.997[0-7.85]$ \\
\hline P. jeffreyi & $1.683[1.03-3.1]$ & $0.937[0.55-1.44]$ & $3.889[0-37.25]$ & 0.98 [0-17.29] \\
\hline \multicolumn{5}{|l|}{ POFLABMA } \\
\hline A. magnifica & 1.09 [0.1-1.82] & $0.935[0.4-1.88]$ & $0.723[0.37-1.43]$ & $0.791[0.19-1.65]$ \\
\hline P. concolor & $0.649[0.1-2.8]$ & $0.421[0-8.28]$ & $1.127[0-4.97]$ & $0.346[0-2.86]$ \\
\hline
\end{tabular}

Of the two fir species, A. magnifica always increased in basal area and density, while $A$. concolor lost BA under climate change in sites SJP and SJM (Figs. 2, 3, 4). A. concolor also exhibited less BA growth under climate change relative to the control at SP and SJ, and reduced density increases at multiple sites. Abies magnifica, on the other hand, exhibited similar density changes across scenarios and a greater increase in BA under climate change in higher elevation plots.

Increases in $P$. lambertiana BA and density were reduced by warming in the two lowest elevation plots but increased under moister scenarios at SJ. At SJP and UPLOG, P. lambertiana BA declined but density increased substantially; with warming, the decline in BA was more pronounced and the increase in density smaller. $P$. ponderosa declined in BA and increased in density for all site-scenario combinations except for SP-Control, SJPControl, and SJP-MIROC ("hot-dry") where BA increased (Figs. 2, 3, 4, 5, 6). Pinus jeffreyi increased in both density and BA at SJP and UPLOG, more so in the climate change scenarios, while at SJ they only increased substantially with climate change (Figs. 2, 3, 4).

Calocedrus decurrens decreased in density in all scenarios while usually increasing in BA (Figs. $2 \& 3$ ). The only site-scenario combination that decreased in cedar BA was SP-CCSM ("moderate-warm") but, as there are very few cedars at this site, that could have been due to stochasticity. Warming favored increased BA of Q. kelloggii (Figs. 2 \& 5), while stem density always decreased, but less so with warming at SP and UPLOG (Figs. 3 \& 6).

\section{Discussion}

Our results suggest that, in the absence of disturbance, forests in the southern Sierra Nevada would likely increase in stem density and basal area over the coming decades (Figs. 2 \& 3), particularly at sites with low current density or high BA. The direction of change in total density and BA was the same for the three RCP 8.5 scenarios and 1974-2014 "control" at all sites, as well as for most site-species combinations. Therefore, we chose not to run scenarios RCP 6.0 or 4.5 , as these would almost certainly fall within the same range. For instance, total BA would still likely increase a similar amount across all sites, while $C$. decurrens BA at UPLOG would increase more than the control but less than the RCP 8.5 scenarios. Site-level variation was much higher than between scenarios. The stem density decrease at the lowest site, BBBPIPO, was likely due to higher mortality among the smallest stems, as average pertree BA increased at this site across all scenarios despite modest total BA increases, a pattern that was also seen to a lesser extent in site $\mathrm{SJ}$; increased recruitment decreased average tree BA at the other sites (Fig. 14, Appendix 5). Species-level responses varied more by climate scenario, though site-level variation was still considerable; changes were often consistent in direction between scenarios within a site.

While firs continued to dominate, A. concolor performed worse under warmer conditions at 4 out of 6 sites, while A. magnifica performed as well or better. This is consistent with the individual demographic behaviors: Higher temperatures favored more positive demographic rates in A. magnifica 


\section{Basal Area}
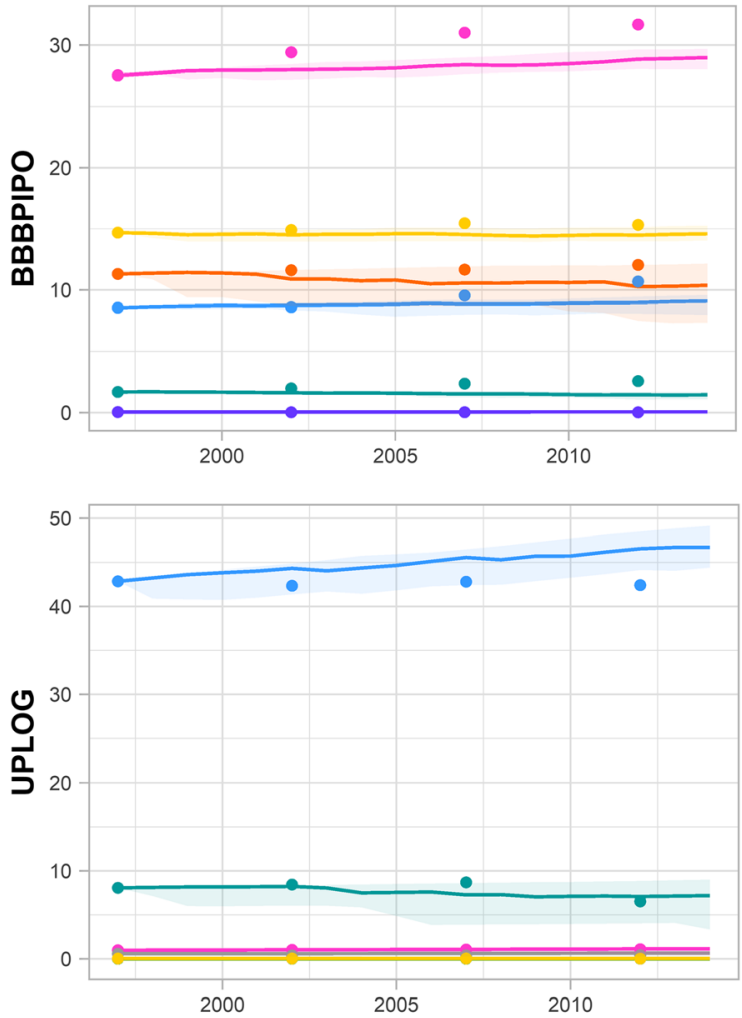

Density

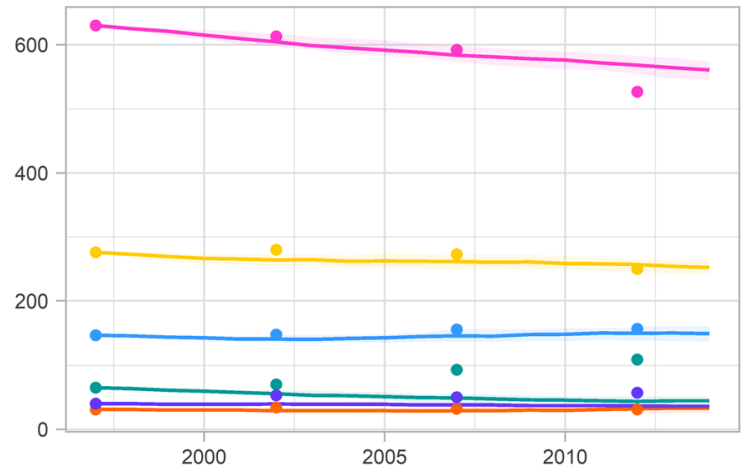

Species

$\rightarrow \mathrm{ABCO}$

$\multimap$ CADE

$\multimap$ PILA

$\because$ PIPO

$\multimap \mathrm{QUCH}$

-0 QUKE

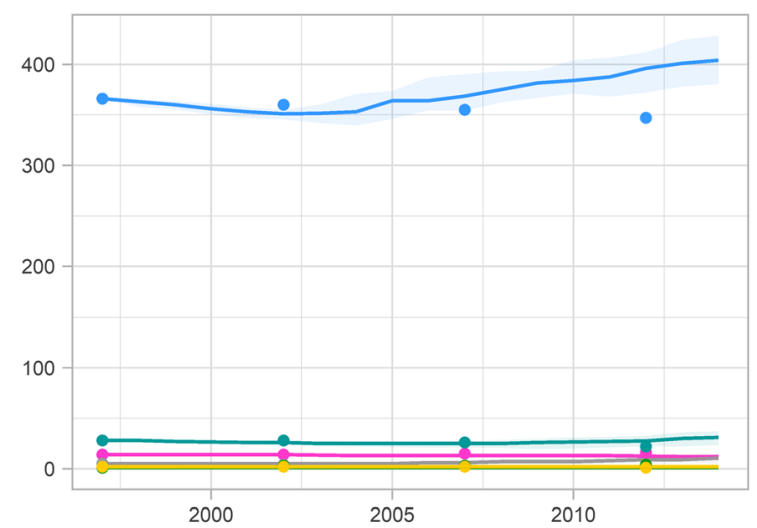

Species

$\multimap \mathrm{ABCO}$

$\rightarrow$ ABMA

$\multimap$ CADE

$\multimap$ PIJE

$\multimap$ PILA

$\multimap$ QUKE

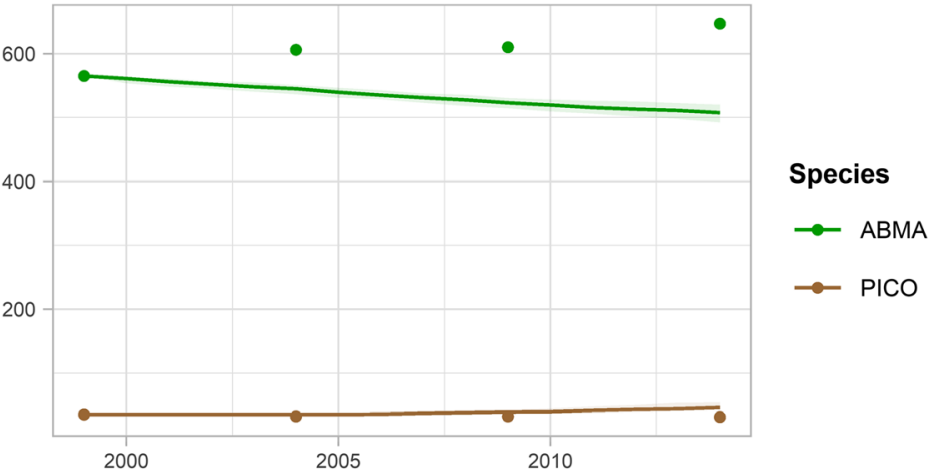

Year

ABMA, A. magnifica; CADE, C. decurrens; PICO, P. contorta; PILA, P. lambertiana; PIPO, P. ponderosa; QUCH, Q. chrysolepis; QUKE, Q. kelloggii

change in density, reflecting increased growth (Fig. 14, Appendix 5).

The biggest winner in the climate change scenarios was $P$. jeffreyi, which exhibited both BA and density increases, though this species also increased at 2 out of 3 sites in the control scenario. The increases in BA were driven primarily by recruitment, leading to steady or declining mean tree BA (Fig. 14, Appendix 5). The positive effects of warm dry conditions on $P$. jeffreyi are consistent with previously observed 

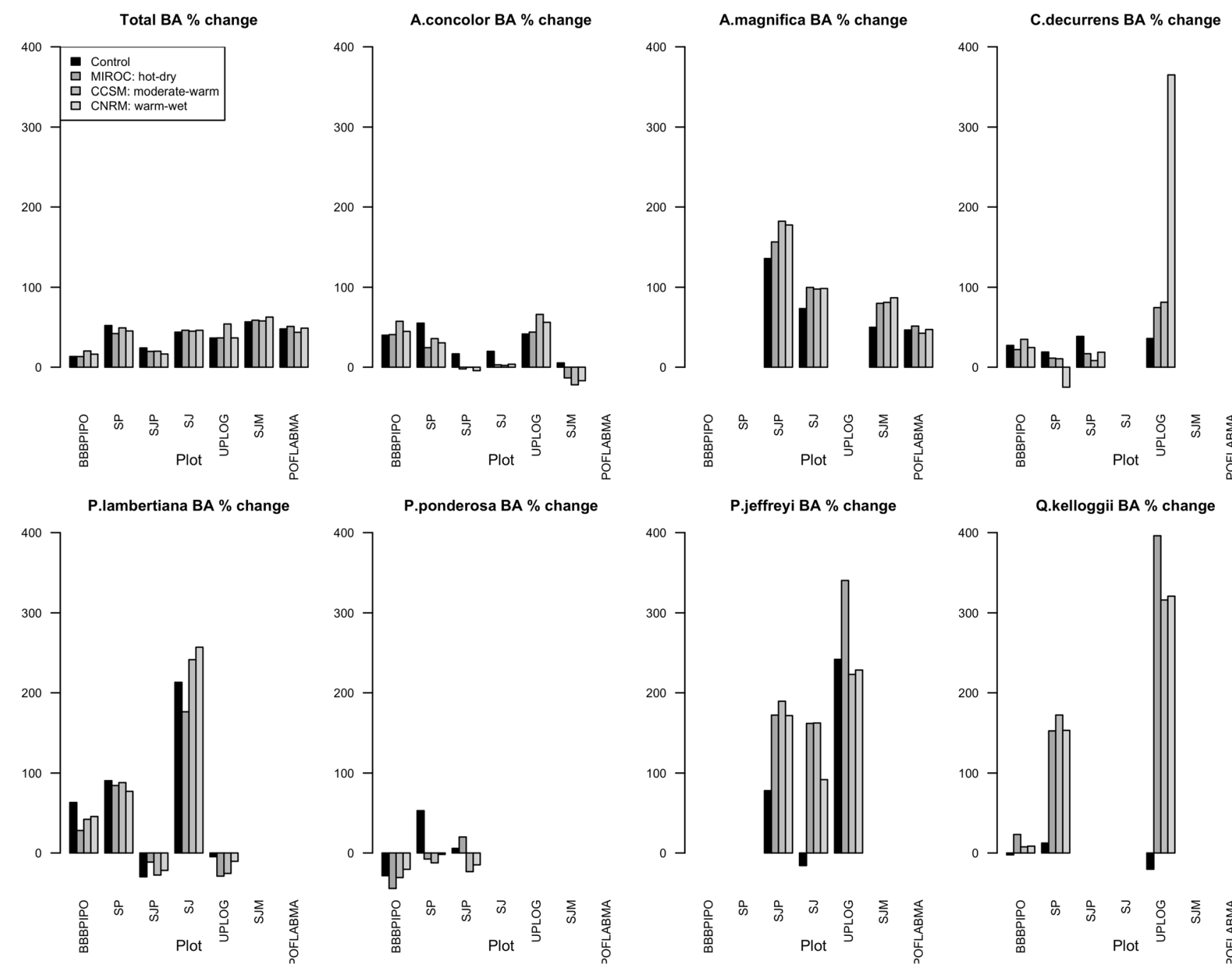

Fig. 2 Average percent change in basal area (BA) under control and climate change scenarios 2006-2099, 10 replicates

adult survival and all growth responses (Table 1) as well as its abundance on the dry eastern side of the Sierra Nevada and broader elevational range in the south (Haller 1959). The responses of $P$. lambertiana were complex, showing increases in density at all sites across climate scenarios but site-specific differences in BA changes. Increases in BA and density at low elevations were reduced with climate change at 1609-1806 m but increased in 2 of the 3 warming scenarios at $2197.6 \mathrm{~m}$. At SJP and UPLOG, however, BA decreased by up to $28.9 \%$, and density increased by as much as $785 \%$, indicating large tree mortality across climate scenarios, which led to a steep decline in mean tree basal area (Appendix 5). Increased winter temperatures boost the growth of adult $P$. lambertiana, but higher summer temperatures negatively affect its survival (Table 1). Pinus lambertiana appears to have unusually high shade-tolerance for a pine (Moran et al. 2019), which may have contributed to its density increases.
Both $C$. decurrens and $Q$. kelloggii are predicted to decrease in density but increase in BA. This was driven by higher mortality and/or lower recruitment of small individuals, leading to increased average tree size (Fig. 14, Appendix 5). Warmer temperatures favor adult growth and survival in Q. kelloggii and adult survival in $C$. decurrens but negatively impact their seedlings (Table 1). Warmer conditions particularly favor increases in total Quercus BA; for C. decurrens, this was only consistently true at the highest site of occurrence (Fig. 2). Both species increased in density during the twentieth century (Dolanc et al. 2014a; McIntyre et al. 2015) and exhibited low mortality in the 2012-2016 "hot drought"(Fettig et al. 2019). Conversely, $P$. ponderosa usually decreased in BA but increased in density; higher temperatures negatively impact $P$. ponderosa survival but boost seedling growth (Table 1). The increase in $P$. ponderosa density was surprising given that this species is fairly shade-intolerant, but the sites containing it 
Total Dens \% change

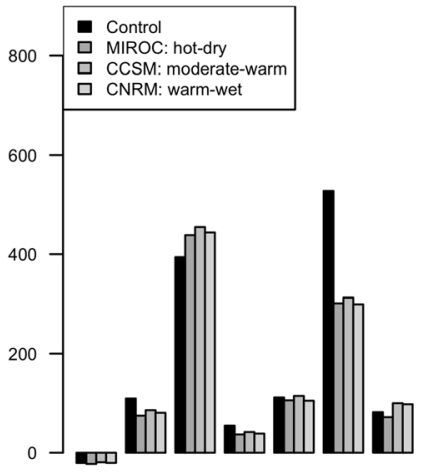

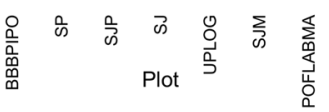

P.lambertiana Dens \% change

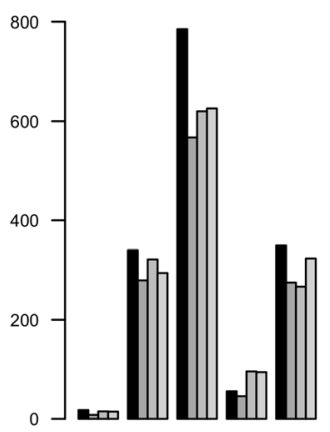

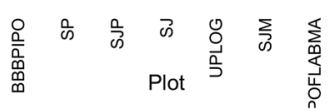

A.concolor Dens \% change

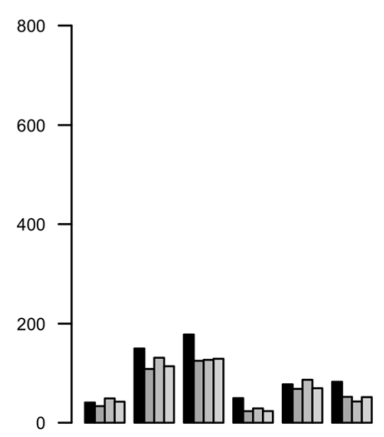

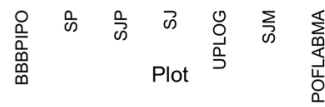

P.ponderosa Dens \% change

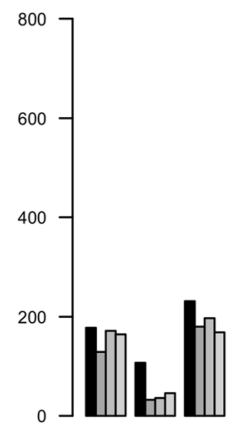

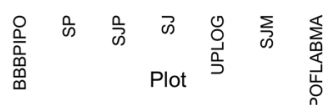

A.magnifica Dens \% change

C.decurrens Dens \% change
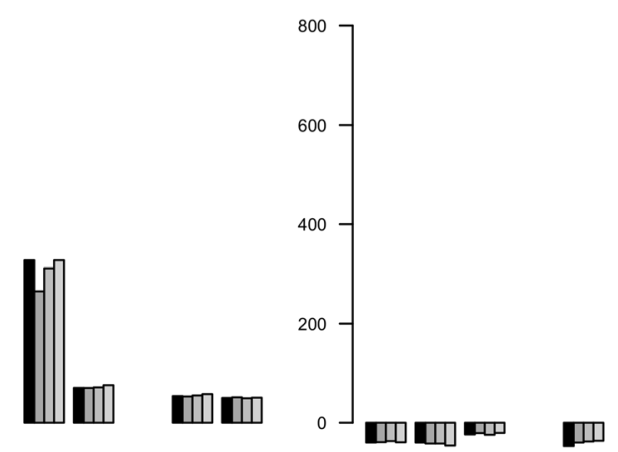

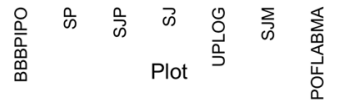

Q.kelloggii Dens \% change
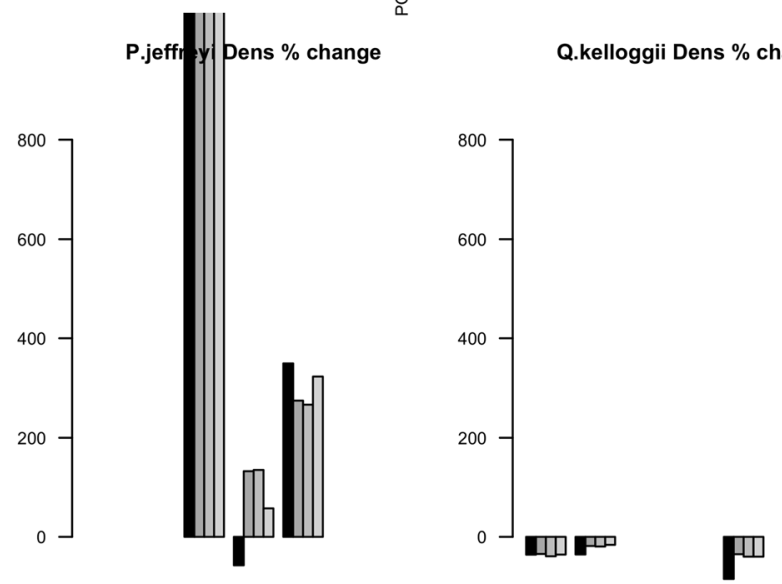

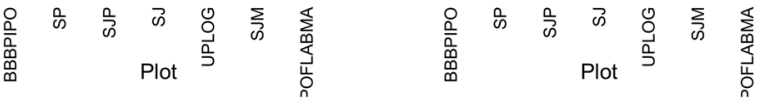

Fig. 3 Average percent change in tree density (\# trees/ha) under control and climate change scenarios 2006-2099, 10 replicates

Fig. 4 Basal area projections, site SJP. Left - P. jeffreyi (PIJE, top) and $A$. concolor (ABCO, bottom) in all 4 climate scenarios: control, MIROC ("hot-dry"), CCSM4 ("moderate-warm"), and CNRM ("warm-wet"). Right - All species in control (top) and "hot-dry" (bottom) scenarios. Solid lines median over 10 replicates.

Shading - 95\% confidence interval. $A B C O$, A. concolor; $A B M A$,

A. magnifica; $C A D E$,

C. decurrens; PILA,

$P$. lambertiana; PIJE, P. jeffreyi; PIPO, P. ponderosa
SJP PIJE

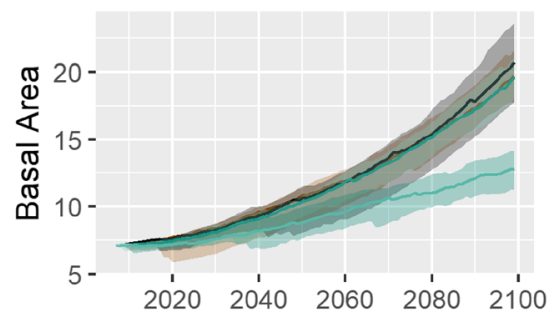

SJP ABCO

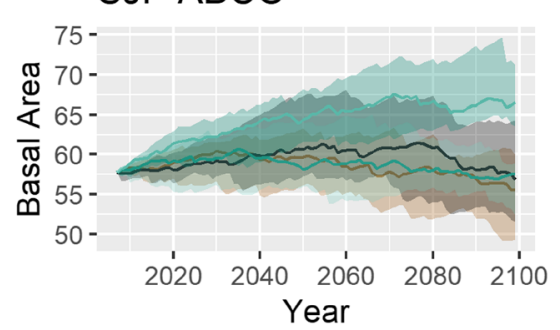

Sequence $-\operatorname{cCSM} 4-$ CNRM - CNTRL - MIROC
SJP CNTRL

$60-$

$40-$

$20-$

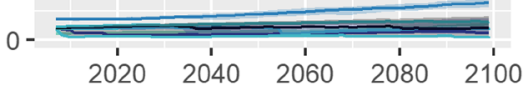

SJP MIROC

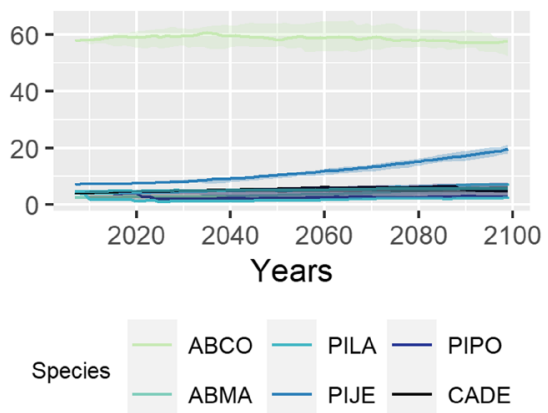

INRA פ⿴囗S pringer 
Fig. 5 Basal area projections, site SP. Left - Q. kelloggii (QUKE, top) and $P$. ponderosa (PIPO, bottom) in all 4 climate scenarios: control, MIROC ("hot-dry"),

CCSM4 ("moderate-warm"), and CNRM ("warm-wet"). Right - All replicates. Shading - 95\% confidence interval. $A B C O$,

A. concolor; $C A D E$,

C. decurrens; PILA,

P. lambertiana; $P I P O$,

P. ponderosa; $Q U C H$,

Q. chrysolepis; QUKE,

Q. kelloggii. species in control (top) and "hotdry". Solid lines - median over 10

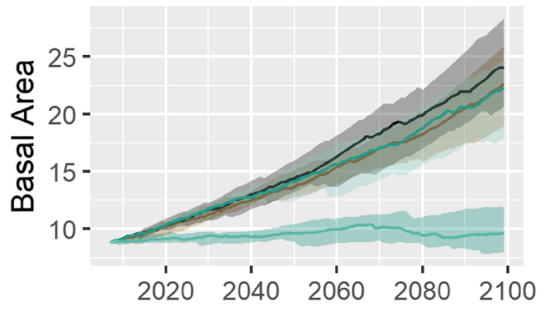

SP PIPO

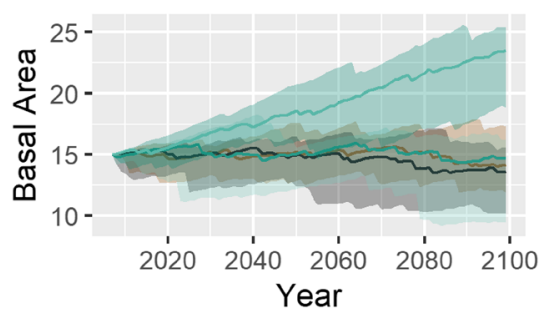

iequence $-\operatorname{cCSM} 4-\mathrm{CNRM}-\mathrm{CNTRL}-$ MIROC
SP QUKE
SP CNTRL

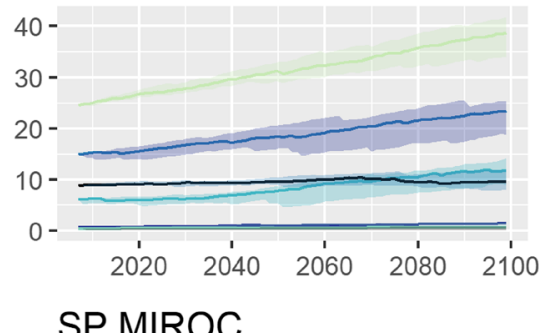

SP MIROC

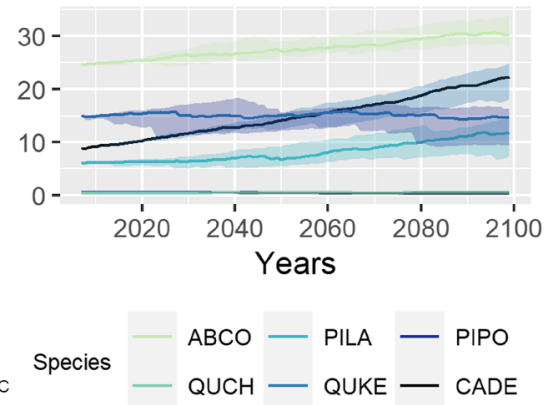

had more gaps at the start of the simulation. In addition, $P$. ponderosa seedlings benefit from modest levels of neighboring adult basal area (Moran et al. 2019).

Increases in forest density and declines in large trees occurred across California during the twentieth century (McIntyre et al. 2015), but this trend was most pronounced in private timberlands, and densification was greater on nonwilderness National Forest lands than in National Parks (Easterday et al. 2018). Both our USGS and newly established plots have had no management interventions other than, in some cases, prescribed fire, since at least the 1980 s (Appendix 2). Trajectories for more disturbed sites might differ, so we would encourage those who are interested in National Forest or private timberlands to apply the parameterized model to their specific sites. Climate projections for various GCMRCP combinations can be downloaded from the California Climate Commons (http://climate.calcommons.org/bcm).

A prior study modeling 30 -year stand growth projected lower stem volume growth under climate change, more so for 20-year-old $P$. ponderosa plantations than for mature second-growth stands (Battles et al. 2008), which is consistent with some but not all of our results. However, the model in question (CACTOS) was designed to estimate timber production and has rather basic ingrowth and mortality functions.
Fig. 6 Tree density projections, site SP. Left - Q. kelloggii (QUKE, top) and P. ponderosa (PIPO, bottom) in all 4 climate scenarios: Control, MIROC ("hot-dry"), CCSM4 ("moderatewarm"), and CNRM ("warmwet"). Right - All species in control (top) and "hot-dry" (bottom) scenarios. Solid lines - median over 10 replicates. Shading - $95 \%$ confidence interval. $A B C O, \mathrm{~A}$. concolor; CADE, C. decurrens; PILA, P. lambertiana; PIPO,

P. ponderosa; $Q U C H$, Q. chrysolepis; QUKE, Q. kelloggii
SP QUKE

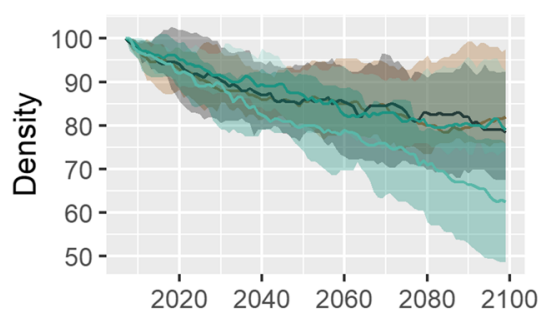

SP PIPO

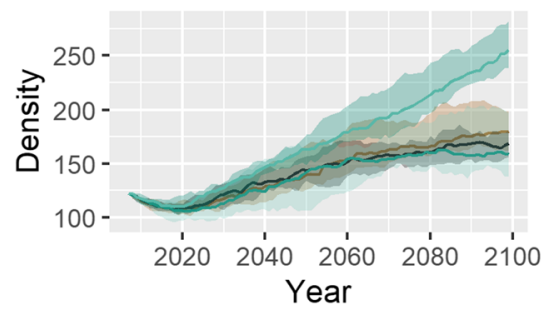

iequence $-\operatorname{CCSM} 4-$ CNRM - CNTRL - MIROC

\section{SP CNTRL}

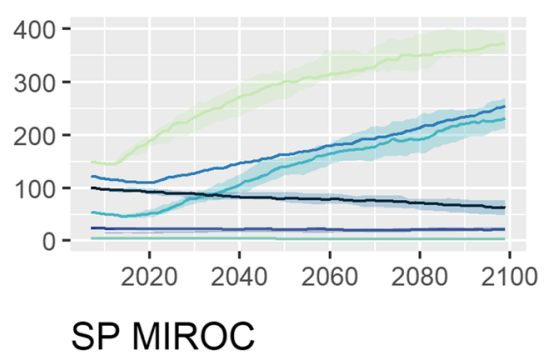

$300-$

200 -

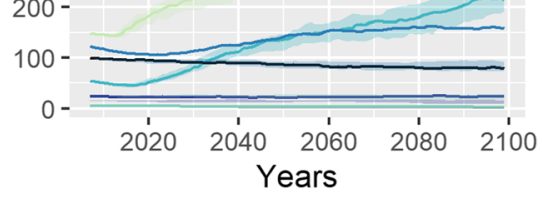

Years

Species

$$
\begin{aligned}
& \text { ABCO - PILA - PIPO } \\
& \text { QUCH - QUKE - CADE }
\end{aligned}
$$


Some of the patterns we observed, such as the increased basal area of Q. kelloggii under climate change (Fig. 5), appeared after the first 30 years. An analysis based on tree growth increment data was more consistent with our findings, projecting increased growth in California forests under climate change both with and without $\mathrm{CO}_{2}$-induced increases in water use efficiency (Charney et al. 2016). Prior landscape-scale vegetation models also predict that climate change favors the recruitment of more drought-tolerant species such as oaks and gray pines (Lenihan et al. 2003; Liang et al. 2017).

Our projections of increased overall forest density would likely change if fire effects were included, but the tendency toward density increases could make fuel management more challenging. Fire suppression since the 1880 s has already led to increasing dominance of firs, higher forest density, and increased risk of severe fires (Beaty and Taylor 2007; Collins et al. 2011; Earles et al. 2014). In the Sierra Nevada, forest area burned per year increases with spring and summer temperatures (Keeley and Syphard 2016). A recent simulation study suggested that thinning and understory burning, while having little effect under contemporary fire regimes, could significantly decrease fire severity, increase carbon sequestration stability, and maintain net ecosystem exchange under projected extreme fire weather (Krofcheck et al. 2017). The Liang et al. model (2017) included climate-associated increases in wildfire and predicted a reduction in landscape $\mathrm{C}$ sequestration potential. The impacts of both low and high intensity fire should be included in future analyses if projections are to be used to guide management. SORTIE-ND includes several fire behaviors; however, our aim here was to examine direct climate effects.

Another source of mortality that can be influenced by climate is disease and pest outbreaks. In the 2012-2016 drought, various species of bark beetles were the proximate cause of death for many trees, particularly large pines (Fettig et al. 2019). The transmission and effects of fungal pathogens, such as the blister rust that affects sugar and western white pines, on the other hand, are favored by wet conditions (Tomback and Achuff 2010). However, these effects are challenging to include in forest simulators, as host and herbivore/pathogen dynamics interact.

Early seedling survival proved to have a strong influence on adult and sapling density. Parameterizing these dynamics can be challenging, as very young seedlings are difficult to detect and individually tag. We plan to address this in future iterations of the model. Including soil properties might also be important for local dynamics, as the model does not currently account for rock outcrops, soil depth, or low nutrients that might limit tree establishment and growth. However, such data are not always recorded for long-term forest monitoring plots.
In interpreting both total and species-level responses, it is important to remember that models are parameterized based on observed variation. For the 26 parameterization plots, maximum July temperatures increased $1-3{ }^{\circ} \mathrm{C}$ since the 1970s, but changes in January minimums were smaller and average precipitation did not change (Moran et al. 2019). Growth sensitivity to climate has been observed to shift over time (Wilmking et al. 2020); this may also be true of mortality and fecundity responses. The same is true of emissions scenarios, which are subject to change due to human policies and behaviors. Therefore, projections beyond $50-100$ years should be considered indicative of direction and magnitude of possible changes but not precise predictions.

\section{Conclusion}

This is the first time an individual-based simulator has been applied to California Mediterranean-climate forests. It is encouraging that, despite increasing temperaturedriven aridity, the model does not project a collapse of tree diversity or basal area due to climate change alone over the next century. Indeed, while shifts in forest composition favoring more heat- and drought-tolerant species are likely, tree densities and basal areas are projected to increase in the absence of disturbance, particularly above $2000-\mathrm{m}$ elevation. However, these results should not be taken as reason to be complacent, as increasing density plus the drying effects of higher summer temperature could contribute to increased risk of severe wildfire. Our results also suggest a need to better understand tree reproduction, as changes in tree density were quite sensitive to these processes and seed production can be both directly and indirectly influenced by climate (Clark et al. 2021).

\section{Appendix 1. Model choice and setup}

\section{Why SORTIE-ND?}

As cited in the main text, several forest models have been parameterized for California forests. However, most are not individual-level models, which is what was required for our future plans of investigating the impact of individual-level variation and heritability in climate responses on forest dynamics under climate change. Liang et al. (2017) used the landscape-scale model LANDIS II, in which species are represented by biomass in age cohorts. Lenihan et al. (2003) used MAPSS-CENTURY 1, a dynamic vegetation model that simulates vegetation types in grid cells of $>900 \mathrm{~m}^{2}$ over very large landscapes. CACTOS (Battles et al. 2008) does track 
individuals but was designed to capture short-term stand growth and includes only simple mortality and in-growth functions. Charney et al. (2016) used an entirely different approach, correlating growth rings with climate, grouping sites according to their climate responses, calculating vulnerability indexes based on projected climate change and local growth responsiveness, and using this to forecast changes in growth under different scenarios.

We considered various other individual-based modeling approaches (Bugmann 2001), including FORCLIM (Bugmann 1996), FORSKA (Prentice et al. 1993), JABOWA (Kienast 1991), and PPA (Purves 2008). However, FORCLIM uses cohorts to describe trees of the same species and age rather than fully treating them as individuals; the source code was also difficult to find. FORSKA does not track individuals under 1-cm DBH. The most recent JABOWA code was not available without purchase, and the model does not track seedlings and treats each canopy as covering an entire patch. PPA is a SORTIE descendant that includes physiological responses but does not track demography on as fine a scale. SORTIE-ND offered high accessibility with the ability to download old model behaviors and upload novel behaviors for other users to access; a history of success with applications to multiple forest types; and pre-existing behaviors that were relatively simple to modify for the type of forest demography data we had available. Moreover, the Battle lab at UC Berkeley is developing SORTIE-NDcompatible tree-shrub competition behaviors (personal communication) that could be combined with our future studies.

\section{Additional references}

Bugmann HKM (1996) A simplified forest model to study species composition along climate gradients. Ecology. 77(7): 2055-2074.

Bugmann HKM (2001) A review of forest gap models. Climatic Change. 51: 259-305. 10.1023/A:1012525626267

Kienast F (1991) Simulated effects of increasing atmospheric $\mathrm{CO}_{2}$ and changing climate on the successional characteristics of Alpine forest ecosystems. Landscape Ecology. 5: 225-238. 10.1007/BF00141437

Prentice IC, Sykes MT, Cramer W (1993) A simulation model for the transient effects of climate change on forest landscapes. Ecological Modelling. 65(1-2): 51-70. 10.1016/ 0304-3800(93)90126-D

Purves DW, Lichstein JW, Strigul N, et al. (2008) Predicting and understanding forest dynamics using a simple tractable model. Proceedings of the National Academy of

\section{Plot setup}

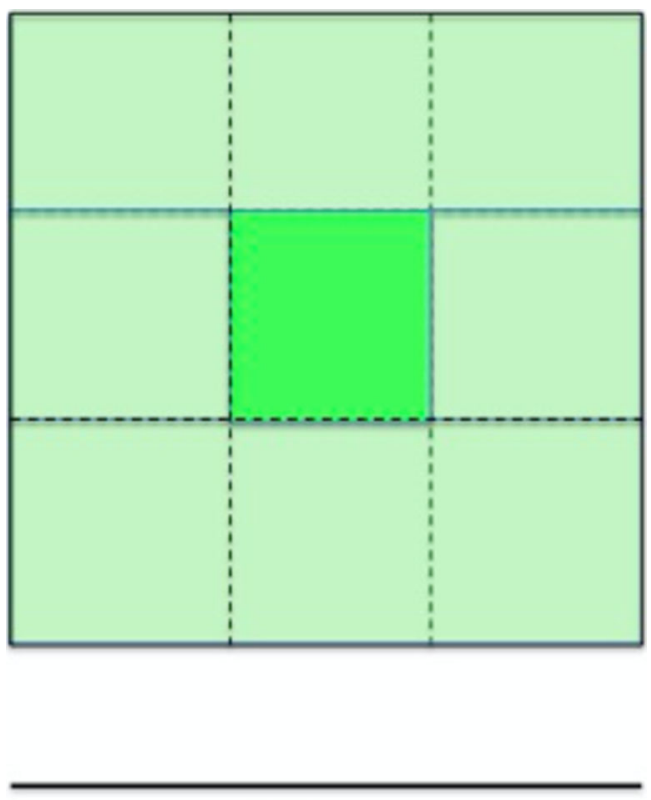

$300 \mathrm{~m}$

Fig. 7 Landscape setup. Darker green square is the focal area, lighter green area the buffer region. Each square is initiated with a replicate of the real tree map

Sciences. 105(44): 17018-17022. https://doi.org/10.1073/ pnas. 0807754105

\section{Climate sequences}

As mentioned in the main text, we focused on January minimum temperature, July maximum temperature, and annual precipitation. These variables were chosen for consistency with the prior published statistical analyses used to parameterize the seedling growth and survival and adult growth behaviors. While the absolute minimum/ maximum temperatures do not always occur in January or July, these monthly minimums are closely correlated with overall winter and summer minima and maxima. Examples of changes in these values under different climate change scenarios are shown in the figure below. 
BBBPIPO
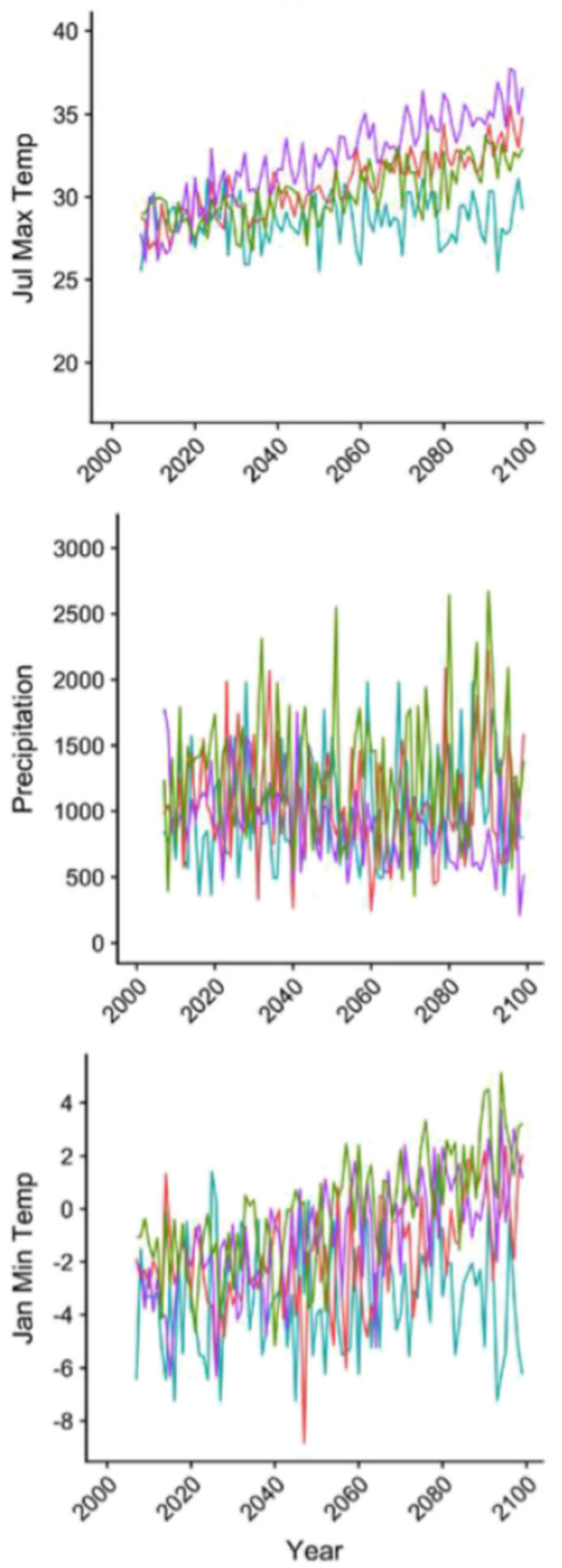

UPLOG
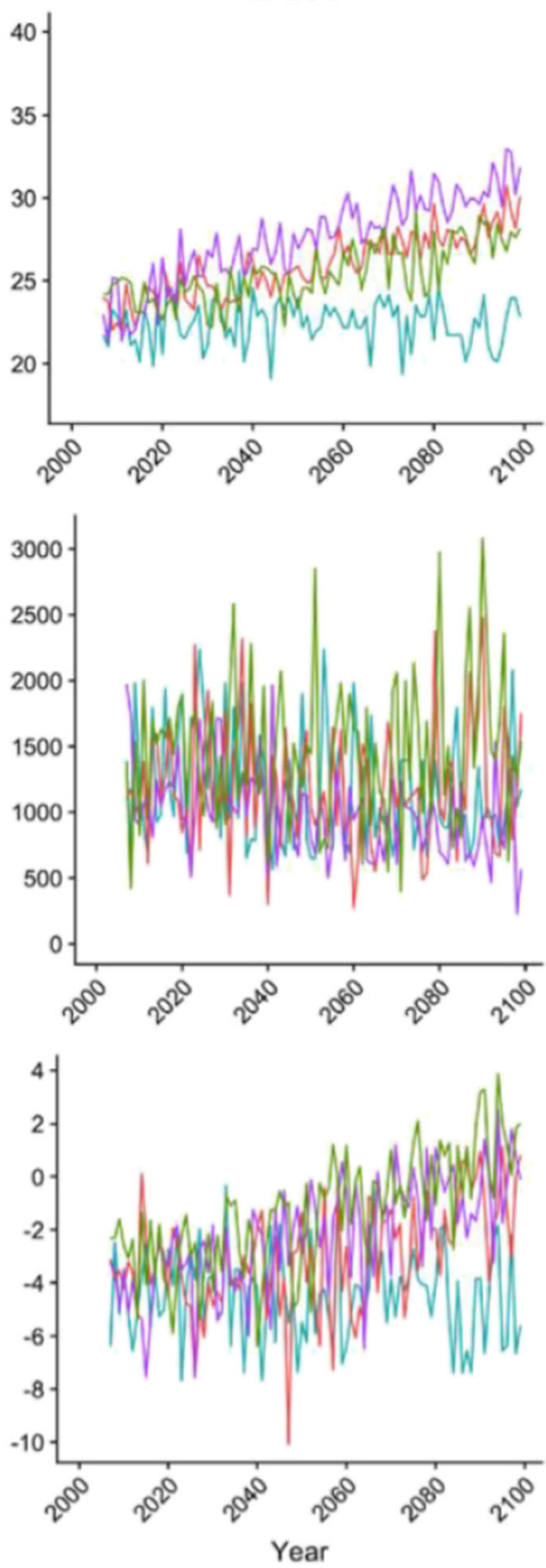

POFLABMA
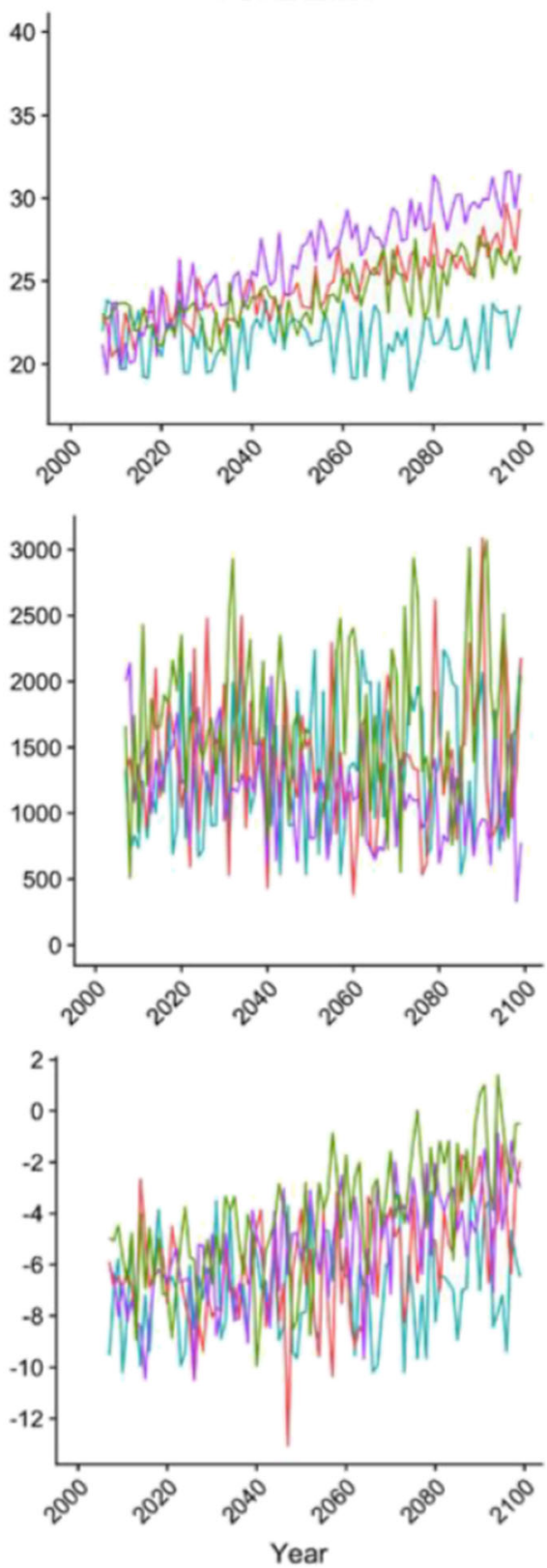

Climate Sequence - CCSM - CNRM - Current - MIROC

Fig. 8 Projected future climate sequences from 2006 to 2099 for three hindcast plots based on MIROC ("hot-dry"), CCSM ("moderate-warm"), and CNRM ("warm-wet") GCMs for RCP 8.5. Figure also includes the "current" or control sequence drawn from the observed historical sequence. July maximum temperature $\left({ }^{\circ} \mathrm{C}\right)$, precipitation $(\mathrm{mm})$, and January minimum temperature $\left({ }^{\circ} \mathrm{C}\right)$ 


\section{Current SORTIE parameters}

\section{Allometry}

$A B C O$, A. concolor; ABMA, A. magnifica; CADE,

C. decurrens; PICO, P. contorta; PIJE, P. jeffreyi; PIMO,

P. monticola; PIPO, P. ponderosa; QUCH, Q. chrysolepis;

QUKE, Q. kellogii

\begin{tabular}{|c|c|c|c|c|c|c|c|c|c|c|}
\hline & $\mathrm{ABCO}$ & ABMA & CADE & $\mathrm{PICO}$ & PIJE & PILA & PIMO & PIPO & QUCH & QUKE \\
\hline Slope of DBH to D at $10 \mathrm{~cm}$ relationship & 0.75 & & & & & & & & & \\
\hline Intercept of DBH to D at $10 \mathrm{~cm}$ relationship & 0 & & & & & & & & & \\
\hline Maximum tree height, in meters & 70 & 70 & 50 & 50 & 60 & 70 & 60 & 65 & 30 & 30 \\
\hline Slope of asymptotic height & 0.011 & 0.010 & 0.010 & 0.019 & 0.016 & 0.009 & 0.016 & 0.016 & 0.011 & 0.011 \\
\hline Slope of height-D at $10 \mathrm{~cm}$ relationship & 0.02 & & & & & & & & & \\
\hline Slope of asymptotic crown radius & 0.079 & 0.060 & 0.086 & 0.072 & 0.072 & 0.074 & 0.061 & 0.077 & 0.133 & 0.126 \\
\hline Crown radius exponent & 1 & & & & & & & & & \\
\hline Maximum crown radius (standard) (m) & 10 & & & & & & & & & \\
\hline Slope of asymptotic crown height & 0.504 & 0.513 & 0.476 & 0.535 & 0.535 & 0.504 & 0.607 & 0.504 & 0.421 & 0.3937 \\
\hline Crown height exponent & 1 & & & & & & & & & \\
\hline
\end{tabular}

Adult diameter growth (behavior "ClimateNCIGrowth")

\begin{tabular}{|c|c|c|c|c|c|c|c|c|c|c|}
\hline & $\mathrm{ABCO}$ & ABMA & CADE & $\mathrm{PICO}$ & PIJE & PILA & PIMO & PIPO & QUCH & QUKE \\
\hline Intercept & $\begin{array}{l}2.68 \\
\text { E-01 }\end{array}$ & $\begin{array}{l}4.00 \\
\mathrm{E}-01\end{array}$ & $\begin{array}{l}1.77 \\
\mathrm{E}-01\end{array}$ & $\begin{array}{l}-3.25 \\
\mathrm{E}-01\end{array}$ & $\begin{array}{l}3.31 \\
\mathrm{E}-01\end{array}$ & $\begin{array}{l}3.64 \\
\text { E-01 }\end{array}$ & $\begin{array}{l}1.60 \\
\text { E-01 }\end{array}$ & $\begin{array}{l}2.12 \\
\mathrm{E}-01\end{array}$ & $\begin{array}{l}-3.37 \\
\text { E- } 01\end{array}$ & $\begin{array}{l}4.05 \\
\text { E- } 01\end{array}$ \\
\hline DBH effect & \multicolumn{10}{|c|}{$\begin{array}{r}1.34 \\
\text { E-03 }\end{array}$} \\
\hline NCI effect & \multicolumn{10}{|c|}{$\begin{array}{c}-2.27 \\
\text { E-04 }\end{array}$} \\
\hline JanMin effect & $\begin{array}{l}4.88 \\
\text { E-03 }\end{array}$ & $\begin{array}{l}4.82 \\
\text { E-03 }\end{array}$ & $\begin{array}{l}-3.40 \\
\text { E-03 }\end{array}$ & $\begin{array}{l}-6.66 \\
\text { E-02 }\end{array}$ & $\begin{array}{l}1.78 \\
\text { E-02 }\end{array}$ & $\begin{array}{l}3.93 \\
\text { E-03 }\end{array}$ & $\begin{array}{l}3.23 \\
\text { E-03 }\end{array}$ & $\begin{array}{l}-2.62 \\
\text { E-02 }\end{array}$ & $\begin{array}{l}-6.43 \\
\text { E-02 }\end{array}$ & $\begin{array}{l}1.95 \\
\text { E-02 }\end{array}$ \\
\hline Precip effect & $\begin{array}{l}5.30 \\
\text { E-05 }\end{array}$ & $\begin{array}{l}-7.62 \\
\text { E-05 }\end{array}$ & $\begin{array}{l}6.85 \\
\text { E-05 }\end{array}$ & $\begin{array}{l}4.21 \\
\text { E-05 }\end{array}$ & $\begin{array}{l}-3.37 \\
\text { E-05 }\end{array}$ & $\begin{array}{l}-5.39 \\
\text { E-05 }\end{array}$ & $\begin{array}{l}1.28 \\
\text { E-04 }\end{array}$ & $\begin{array}{l}6.77 \\
\text { E-06 }\end{array}$ & $\begin{array}{l}3.71 \\
\text { E-04 }\end{array}$ & $\begin{array}{l}-8.95 \\
\text { E-05 }\end{array}$ \\
\hline NCI max crowding distance (m) & \multicolumn{10}{|c|}{50} \\
\hline
\end{tabular}

$D B H$, diameter at breast height $(\mathrm{cm}) ; N C I$, neighborhood crowding index; JanMin, minimum January temperature; Precip total annual precipitation; Crowding distance, distance from target tree for which crowding effects are calculated 
Seedling height growth

(behavior "ClimateSeedlingHeightGrowth")

\begin{tabular}{|c|c|c|c|c|c|c|c|c|c|c|}
\hline & $\mathrm{ABCO}$ & ABMA & CADE & $\mathrm{PICO}$ & PIJE & PILA & PIMO & PIPO & QUCH & QUKE \\
\hline Intercept & -1.01 & -6.1 & -1.53 & -4.2 & -4.2 & -4.51 & -2.91 & -4.57 & -2.5 & -2.5 \\
\hline Size effect 0 (1st \& 2 nd yr) & 6.04 & & & & & & & & & \\
\hline Size effect $1(<10 \mathrm{~cm})$ & 6.04 & & & & & & & & & \\
\hline Size effect $2(10-50 \mathrm{~cm})$ & 2.71 & & & & & & & & & \\
\hline Size effect $3(50-140 \mathrm{~cm})$ & 2.95 & & & & & & & & & \\
\hline July maximum temperature & -0.158 & 0.020 & -0.115 & 0.030 & 0.030 & -0.012 & -0.063 & 0.033 & -0.129 & -0.129 \\
\hline Current precipitation & $\begin{array}{l}-2.77 \\
\text { E-04 }\end{array}$ & $\begin{array}{l}-3.30 \\
\text { E-05 }\end{array}$ & $\begin{array}{l}-1.47 \\
\text { E-04 }\end{array}$ & $\begin{array}{l}-1.25 \\
\text { E-03 }\end{array}$ & $\begin{array}{l}-1.25 \\
\text { E-03 }\end{array}$ & $\begin{array}{l}-3.67 \\
\text { E-04 }\end{array}$ & $\begin{array}{l}-8.86 \\
\text { E-04 }\end{array}$ & $\begin{array}{l}-1.14 \\
\text { E-03 }\end{array}$ & $\begin{array}{l}4.52 \\
\text { E-04 }\end{array}$ & $\begin{array}{l}4.52 \\
\text { E-04 }\end{array}$ \\
\hline Basal area & -0.033 & 0.041 & -0.164 & 0.019 & 0.019 & -0.080 & -0.328 & 0.041 & -0.017 & -0.017 \\
\hline
\end{tabular}

Adult mortality (behavior "ClimateNCIMortality")

\begin{tabular}{|c|c|c|c|c|c|c|c|c|c|c|}
\hline & $\mathrm{ABCO}$ & ABMA & CADE & $\mathrm{PICO}$ & PIJE & PILA & PIMO & PIPO & QUCH & QUKF \\
\hline Intercept & -4.012 & & & & & & & & & \\
\hline Diam & -0.031 & & & & & & & & & \\
\hline $\operatorname{Diam}^{2}$ & $1.65 \mathrm{E}-04$ & & & & & & & & & \\
\hline $\mathrm{NCI}$ & $9.92 \mathrm{E}-05$ & & & & & & & & & \\
\hline JulMax & $-1.21 \mathrm{E}-03$ & $-1.35 \mathrm{E}-02$ & $-1.56 \mathrm{E}-02$ & $\begin{array}{l}7.88 \\
\text { E-02 }\end{array}$ & $\begin{array}{l}-2.48 \\
\text { E-02 }\end{array}$ & $\begin{array}{l}2.82 \\
\text { E-02 }\end{array}$ & $\begin{array}{l}-8.05 \\
\text { E-02 }\end{array}$ & $\begin{array}{l}1.51 \\
\text { E-02 }\end{array}$ & $\begin{array}{l}-3.27 \\
\text { E-02 }\end{array}$ & $\begin{array}{l}-9.28 \\
\text { E-03 }\end{array}$ \\
\hline Precip & $\begin{array}{r}-1.93 \\
\text { E-04 }\end{array}$ & $\begin{array}{l}-1.21 \\
\text { E-04 }\end{array}$ & $\begin{array}{l}-6.03 \\
\text { E-05 }\end{array}$ & $\begin{array}{l}-2.75 \\
\text { E-03 }\end{array}$ & $\begin{array}{l}3.67 \\
\text { E-04 }\end{array}$ & $\begin{array}{l}-6.84 \\
\text { E-05 }\end{array}$ & $\begin{array}{l}-6.12 \\
\text { E-04 }\end{array}$ & $\begin{array}{l}-2.68 \\
\text { E-04 }\end{array}$ & $\begin{array}{l}2.36 \\
\text { E-04 }\end{array}$ & $\begin{array}{l}1.66 \\
\text { E-04 }\end{array}$ \\
\hline NCI Max crowding distance (m) & 100 & & & & & & & & & \\
\hline
\end{tabular}

Seedling survival

(behavior "ClimateSeedlingHeightSurvival")

\begin{tabular}{|c|c|c|c|c|c|c|c|c|c|c|}
\hline & $\mathrm{ABCO}$ & ABMA & CADE & $\mathrm{PICO}$ & PIJE & PILA & PIMO & PIPO & QUCH & QUKE \\
\hline Intercept & 5.72 & 6.6 & 7.65 & 5.88 & 5.88 & 6.34 & 6.49 & 5.7 & 7.19 & 7.19 \\
\hline Size effect 0 (1st \& 2 nd yr) & -17 & -12 & -20 & -10 & -7 & -7 & -10 & -10 & -10 & -15 \\
\hline $\begin{array}{l}\text { Size effect } 1 \\
(<10 \mathrm{~cm})\end{array}$ & -11 & -8 & -15 & -7 & -5 & -5 & -7 & -7 & -10 & -10 \\
\hline Size effect $2(10-50 \mathrm{~cm})$ & & & & & -0.83 & & & & & \\
\hline Size effect $3(50-140 \mathrm{~cm})$ & & & & & 0.27 & & & & & \\
\hline July maximum temperature & -0.072 & -0.119 & -0.126 & -0.053 & -0.053 & -0.089 & 0.027 & -0.072 & -0.141 & -0.141 \\
\hline Precipitation & $-2.20 \mathrm{E}-05$ & $-3.20 \mathrm{E}-05$ & $1.90 \mathrm{E}-05$ & $5.10 \mathrm{E}-05$ & $5.10 \mathrm{E}-05$ & $2.00 \mathrm{E}-06$ & $4.00 \mathrm{E}-05$ & $1.10 \mathrm{E}-05$ & $\begin{array}{l}1.47 \mathrm{E} \\
-04\end{array}$ & $\begin{array}{l}1.47 \mathrm{E} \\
-04\end{array}$ \\
\hline BA & 0.01 & -0.078 & -0.109 & 0.044 & 0.044 & -0.049 & 2.204 & 0.091 & -0.17 & -0.17 \\
\hline BA threshold & 33.0 & 33.0 & 6.0 & 10.0 & 10.0 & 31.0 & 3.0 & 4.0 & 4.0 & 7.0 \\
\hline
\end{tabular}


Fecundity and dispersal

(behavior "MastingSpatialDisperse")

\begin{tabular}{|c|c|c|c|c|c|c|c|c|c|c|}
\hline & $\mathrm{ABCO}$ & ABMA & CADE & PICO & PIJE & PILA & PIMO & PIPO & QUCH & QUKE \\
\hline Min DBH for reprod., $(\mathrm{cm})$ & 23 & 23 & 15 & 21 & 21 & 30 & 16 & 22 & 10 & 14 \\
\hline Masting CDF “a”" & \multicolumn{10}{|c|}{3} \\
\hline Masting CDF "b" & \multicolumn{10}{|c|}{-5} \\
\hline STR draw PDF & \multicolumn{10}{|c|}{ ZIP } \\
\hline Canopy function & \multicolumn{10}{|c|}{$2 \mathrm{Dt}$} \\
\hline Non-masting STR mean & 5.71 & 5.71 & 4.78 & 1.66 & 1.66 & 1.66 & 1.66 & 1.66 & 0.27 & 0.27 \\
\hline Non-masting STR standard deviation & 0.05 & 0.05 & 0.74 & 0.044 & 0.044 & 0.044 & 0.044 & 0.044 & 0.044 & 0.044 \\
\hline Lognormal canopy X0 & \multicolumn{10}{|c|}{1} \\
\hline TWODT canopy Xb & \multicolumn{10}{|c|}{1} \\
\hline TWODT canopy X0 & 4167 & 4167 & 536 & 6447 & 6447 & 6447 & 6447 & 6447 & 1084 & 1084 \\
\hline Non-mast proportion participating $(0-1)$ & \multicolumn{10}{|c|}{1} \\
\hline Masting STR mean & 56.23 & 56.23 & 45.45 & 6.39 & 6.39 & 6.39 & 6.39 & 6.39 & 1.02 & 1.02 \\
\hline Masting STR st dev & 0.14 & 0.14 & 0.23 & 0.078 & 0.078 & 0.078 & 0.078 & 0.078 & 0.062 & 0.062 \\
\hline Masting Twodt Xb & \multicolumn{10}{|c|}{1} \\
\hline Masting Twodt X0 & 4167 & 4167 & 536 & 6447 & 6447 & 6447 & 6447 & 6447 & 1084 & 1084 \\
\hline Mast proportion participating $(0-1)$ & \multicolumn{10}{|c|}{1} \\
\hline Masting group & 1 & 2 & 3 & 4 & 5 & 6 & 7 & 8 & 9 & 10 \\
\hline
\end{tabular}

\section{Appendix 2. Adult mortality analysis}

Trees in the 26 long-term census plots (Table 4) maintained by the USGS in Yosemite and Sequoia National Parks were checked annually for mortality.

Table. 4 Species listed in order of abundance; bold $=>40 \%$ of stems, italics $=<10 \%$ of stems. Burn? $=$ Time of any prescribed burns. $A B C O$, A. concolor; ABMA, A. magnifica; CADE, C. decurrens; PICO, P. contorta; PIJE, P. jeffreyi; PIMO, P. monticola; PIPO, P. ponderosa; QUCH, Q. chrysolepis; QUKE, Q. kellogii; YNP, Yosemite National Park; SNP, Sequoia National Park; Est, establishment year

\begin{tabular}{|c|c|c|c|c|c|c|}
\hline Plot & Park & Elev (m) & Size (ha) & Est & Burn? & Species \\
\hline YOHOPIPO & YNP & 1500 & 1 & 1991 & 2007 & ABCO, CADE, PILA, PIPO, PSME, QUKE \\
\hline BBBPIPO & SNP & 1609 & 1 & 1992 & NA & CADE, QUKE, ABCO, PILA, PIPO, QUCH \\
\hline CCRPIPO & SNP & 1637 & 1.1 & 1991 & NA & ABCO, CADE, QUKE, PILA, PIPO \\
\hline CRCRPIPO & YNP & 1637 & 1 & 1993 & 2009 & ABCO, CADE, PILA, PIPO, QUKE \\
\hline FFS7CONTROL & SNP & 1941 & 1 & 2001 & NA & ABCO, PILA, CADE \\
\hline FFS6BURN & SNP & 2018 & 1 & 2001 & 2001 & ABCO, PILA, QUKE, CADE, PIPO, PIJE \\
\hline FFS5BURN & SNP & 2030 & 1 & 2001 & 2001 & ABCO, CADE, PILA \\
\hline SURIP & SNP & 2033 & 1.4 & 1982 & NA & ABCO, PILA, ABMA, QUKE, PIJE \\
\hline SUABCO & SNP & 2035 & 0.9 & 1983 & NA & ABCO, CADE, PILA, ABMA \\
\hline SUPILA & SNP & 2059 & 1.1 & 1983 & NA & ABCO, PILA, CADE, QUKE \\
\hline FRPIJE & SNP & 2106 & 1 & 1983 & NA & PIJE, $Q U K E, A B C O, C A D E, P I L A, P I M O$ \\
\hline FFS2BURN & SNP & 2128 & 1 & 2001 & 2001 & ABCO, ABMA, PILA, CADE \\
\hline LMCC & SNP & 2128 & 2 & 1982 & NA & ABCO, ABMA, SEGI, PILA \\
\hline LOTHAR & SNP & 2167 & 1.1 & 1984 & 2004 & ABCO, PILA, PIJE \\
\hline LOGSEGI & SNP & 2170 & 2.5 & 1983 & NA & ABCO, ABMA, PILA, SEGI \\
\hline
\end{tabular}


Table. 4 (continued)

\begin{tabular}{lllllll}
\hline UPTHAR & SNP & 2202 & 1 & 1984 & 2004 & ABCO, PIJE, PILA \\
LOLOG & SNP & 2207 & 1.1 & 1985 & NA & ABCO, ABMA, PILA, SEGI, CADE \\
UPLOG & SNP & 2210 & 1 & 1985 & NA & ABCO, PILA, CADE, PIJE, $Q U K E$ \\
LOGPIJE & SNP & 2405 & 1 & 1985 & NA & ABCO, PIJE, ABMA, PILA \\
SFTRABMA & YNP & 2484 & 1 & 1992 & NA & ABMA \\
WTABMA & SNP & 2521 & 1 & 1993 & NA & ABMA, PIMO \\
POFLABMA & YNP & 2542 & 1 & 1994 & NA & ABMA, PICO \\
PGABMA & SNP & 2576 & 1 & 1992 & NA & ABMA \\
EMSALIX & SNP & 2838 & 1 & 1983 & NA & PIMO, PICO \\
EMSLOPE & SNP & 2950 & 1 & 1983 & NA & PIMO, PICO, PIJE, ABMA \\
EMRIDGE & SNP & 3097 & 1.1 & 1984 & NA & PIMO, PICO \\
\hline
\end{tabular}

We used a Bernoulli process to model the mortality process, and estimated the probability of dying with a linear model and a logit link function:

$$
\begin{aligned}
Y_{i, t} \operatorname{Bern}\left(p_{i, t}\right) & \\
\operatorname{logit}\left(p_{i, t}\right)= & \beta_{0}+\beta_{1} D B H_{t}+\beta_{2} D B H_{t}^{2}+\beta_{3} N C I_{i, t} \\
& +\beta_{4}{\operatorname{Clim} 1_{t}+\beta_{5} \operatorname{Clim}_{t}+\varepsilon}^{\varepsilon N\left(0, \sigma^{2}\right)}
\end{aligned}
$$

where $Y_{i, t}$ is the state of the tree $i$ at time $t ; p_{i, t}$ is the associated probability of dying; the $\beta$ 's are a vector of parameters to estimate; and $\varepsilon$ is an error term. Both $D B H$ and $D B H^{2}$ are included as predictors because both very small and very large trees tend to exhibit elevated mortality. Competition is also known as an important predictor of mortality because it decreases the access to resources. We used a simple competition index:
$N C I_{i, t}=\sum_{j=1}^{j=N_{i}} \frac{D_{j, t}}{\operatorname{dist}_{i, j}}$

where $N_{i}$ is the number of neighbors of tree $i, D_{j, t}$ is the diameter of neighbor $j$ in year $t$, and dist $t_{i, j}$ is the distance between trees $i$ and $j$.

To estimate the parameters of the model, we used a Bayesian calibration implemented in $\mathrm{R}$ ( $\mathrm{R}$ core team 2017) using Gibbs sampling. The vector of $\beta$ 's is assigned a multivariate normal prior, and parameter $\sigma^{2}$ an inverse gamma prior. The model was fit for each species individually. To select the climate variables included in the model, we ran the model with pairs of variables: one related to temperature (JulMax or JanMin) and one related to water availability (precipitation, actual evapotranspiration (AET), or April snowpack). The

\begin{tabular}{|c|c|c|c|c|c|c|}
\hline & Intercept & $\mathrm{DBH}$ & $\mathrm{DBH}^{2}$ & NCI & JulMax & Precip \\
\hline \multirow[t]{2}{*}{$\mathrm{ABCO}$} & -4.012 & -0.03078 & 0.0001647 & $9.917 \mathrm{e}-05$ & -0.001214 & $-1.9336 \mathrm{e}-4$ \\
\hline & {$[-4.253 ;-3.771]$} & {$[-0.0332 ;-0.02784]$} & {$[0.0001478 ; 0.0001827]$} & {$[2.327 \mathrm{e}-05 ; 1.681 \mathrm{e}-04]$} & {$[-0.01667 ; 0.01118]$} & {$[-3.2759 \mathrm{e}-4 ;-8.120 \mathrm{e}-5]$} \\
\hline \multirow[t]{2}{*}{ ABMA } & & & & & -0.01354 & $-1.2131 \mathrm{e}-4$ \\
\hline & & & & & {$[-0.02961 ;-0.003055]$} & {$[-2.3956 \mathrm{e}-4 ;-1.3236 \mathrm{e}-6]$} \\
\hline \multirow[t]{2}{*}{ CADE } & & & & & -0.01556 & $-6.0293 e-5$ \\
\hline & & & & & {$[-0.02568 ;-0.003911]$} & {$[-3.2360 \mathrm{e}-4 ; 9.750 \mathrm{e}-5]$} \\
\hline \multirow[t]{2}{*}{ PICO } & & & & & 0.07876 & -0.002746 \\
\hline & & & & & {$[-0.1200 ; 0.1911]$} & {$[-0.004753 ; 0.0003273]$} \\
\hline \multirow[t]{2}{*}{ PIPO } & & & & & 0.01507 & -0.0002683 \\
\hline & & & & & {$[-0.007357 ; 0.04129]$} & {$[-0.0007824 ; 0.0002168]$} \\
\hline \multirow[t]{2}{*}{ PIMO } & & & & & -0.08049 & $-6.122 e-4$ \\
\hline & & & & & {$[-0.1308 ;-0.01762]$} & {$[-1.142 \mathrm{e}-3 ; 8.165 \mathrm{e}-5]$} \\
\hline \multirow[t]{2}{*}{ PIJE } & & & & & -0.02483 & $3.668 \mathrm{e}-4$ \\
\hline & & & & & {$[-0.06274 ; 0.002785]$} & [3.594e-5; 7.837e-4] \\
\hline \multirow[t]{2}{*}{ PILA } & & & & & 0.02819 & $-6.841 e-5$ \\
\hline & & & & & {$[0.01562 ; 0.04794]$} & {$[-3.057 \mathrm{e}-4 ; 1.2326 \mathrm{e}-4]$} \\
\hline \multirow[t]{2}{*}{ QUCH } & & & & & -0.03273 & 0.0002362 \\
\hline & & & & & {$[-0.1087 ; 0.01795]$} & {$[-0.001091 ; 0.001405]$} \\
\hline \multirow[t]{2}{*}{ QUKE } & & & & & -0.009281 & 0.0001655 \\
\hline & & & & & {$[-0.02254 ; 0.008511]$} & {$[-0.0002335 ; 0.0005373]$} \\
\hline
\end{tabular}
combination of variables used in the final model is selected based on DIC values.

Table. 5 Results of the mortality model. Median and $95 \%$ interval for each parameter 


\section{Appendix 3. Fecundity and dispersal analyses}

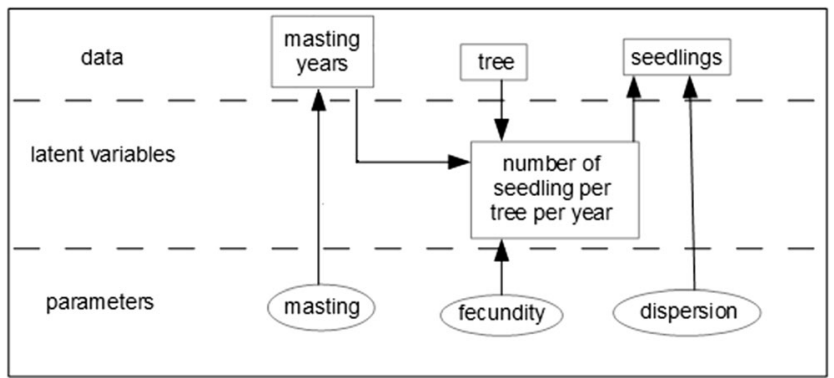

Fig. 9 Fecundity and dispersion model conceptual diagram. Data are tree annual position and the annual number of seedlings in each quadrat. The latent variables are not available and have to be estimated (exact number of seedlings produced by each tree each year). The parameters have to be estimated: the parameters of the masting model, the fecundity model, and the dispersion model

Years are considered masting years if the number of seedlings is higher than the mean number of seedlings. The vector of zeros and ones corresponding to masting or non-masting years is called mast thereafter.

We modeled dispersal using a 2Dt distribution function (Clark et al., 1999a). The number of seedlings of genus $g$ found in quadrat $i$ (area $5 \times 5 \mathrm{~m}$, or $25 \mathrm{~m}^{2}$ ) in year $t$ is:

$m_{g, i, t}=\sum_{j=1}^{J_{g}} 25 \frac{1}{\pi u\left(1+\frac{d_{i, j}^{2}}{u}\right)^{2}} z_{j, t}$ plot do not disperse their seeds far enough to add seedlings in the quadrats of another. The latent variable $z_{j, t}$ must also be estimated.

For $u$, the parameter of the 2Dt function for dispersion, we choose the same weak prior as in Clark et al., (1999b): a Gamma distribution with parameters $(1,0.01)$. For $p_{m}$ and $p_{n}$, the first parameters of the zero-inflated Poisson (ZIP) models for masting and non-masting years respectively; the priors were uniform distributions between 0 and 1 , as it is a probability. For $\lambda_{m}$ and $\lambda_{n}$ the second parameters of the ZIP for masting and non-masting years respectively, a Gamma distribution with parameters $(2,0.01)$.

We used a Gibbs sampler to estimate the parameters and the latent variables (masting years and fecundity for each tree and each year), and a Metropolis-Hastings step at each step of the Gibbs sampler to sample from full conditional distribution. At each time step, the algorithm estimates first $u$; then $p_{m}$ and $p_{n}$; then $\lambda_{m}$ and $\lambda_{n}$; then $z_{j, t}$, the true number of seedlings produced by each tree. Results are presented in Table 6 .

The results suggest that pines have the longest effective dispersal distances (median $u$ equivalent to mean dispersal distance of $126.12 \mathrm{~m}$ ), while cedars disperse the shortest distances (median $u$ equivalent to mean dispersal distance of $36.35 \mathrm{~m}$ ), and firs and oaks are intermediate. $P$ in both masting and nonmasting years is bigger for pines and oaks, indicating a greater variation between individuals in seed output than for firs and

Table. 6 Results of the reproduction and dispersal model. Median and 95\% interval (in brackets and italics) for each parameter and each genus

\begin{tabular}{lllll}
\hline & Abies & Pinus & Quercus & C. decurrens \\
$U$ & 4167 & 6447 & 1083 & 535.6 \\
& {$[4129 ; 4201]$} & {$[6299 ; 6808]$} & {$[930 ; 1307]$} & {$[518.8 ; 552.0]$} \\
$P_{m}$ & 0.2028 & 0.7000 & 0.7113 & 0.5261 \\
& {$[0.1859 ; 0.2139]$} & {$[0.6852 ; 0.7120]$} & {$[0.6703 ; 0.7511]$} & {$[0.5060 ; 0.5464]$} \\
$\lambda_{m}$ & 56.23 & 6.380 & 1.019 & 45.42 \\
$P_{n}$ & {$[55.99 ; 56.52]$} & {$[6.231 ; 6.533]$} & {$[0.8906 ; 1.1443]$} & {$[45.03 ; 45.90]$} \\
& 0.7926 & 0.9198 & 0.9184 & 0.8907 \\
$\lambda_{n}$ & {$[0.7853 ; 0.8000]$} & {$[0.9138 ; 0.9251]$} & {$[0.8866 ; 0.9436]$} & $0.8827 ; 0.8989]$ \\
& 0.2028 & 0.7000 & 0.7113 & 0.5261 \\
& {$[0.1859 ; 0.2139]$} & {$[0.6852 ; 0.7120]$} & {$[0.6703 ; 0.7511]$} & {$[0.5061 ; 0.5464]$}
\end{tabular}

where $d_{i, j}$ is the distance between the center of quadrat $i$ and the tree $j ; J_{g}$ is the number of trees of genus $g$ in the plot; $z_{j, t}$ is the number of seedlings produced by tree $j$ in year $t$, and $u$ is the parameter of the 2Dt function that determines its shape. We estimated $u$ across all plots, but assumed that trees in one cedars. $\lambda_{m}$ is the largest for firs and cedars, which on average produce over 45 new seedlings per tree in a mast year, while the larger-seeded oaks and pines produce 1-6 new seedlings. All species produce on average less than one seedling per tree in a non-mast year, but $\lambda_{n}$ is slightly larger for pines and oaks. 


\section{Appendix 4. Results with unadjusted seedling survival}

These figures depict model output and historical data before the parameters in the seedling survival behavior were changed for class 0 and/or 1. Each graph represents the model replicated 20 times. This runaway basal area and density depicted below was caused by a high early seedling survival rate. To mediate this, the seedling size class 0 parameter was initially decreased at regular intervals (e.g., first made twice as negative, then $4 \times$ as negative) through a series of tests for each USGS site (BBBPIPO, UPLOG, and POFLABMA). After many tests, we concluded that "hand tuning" size class 1 parameter was also needed in order to achieve results similar to the observed historical data.
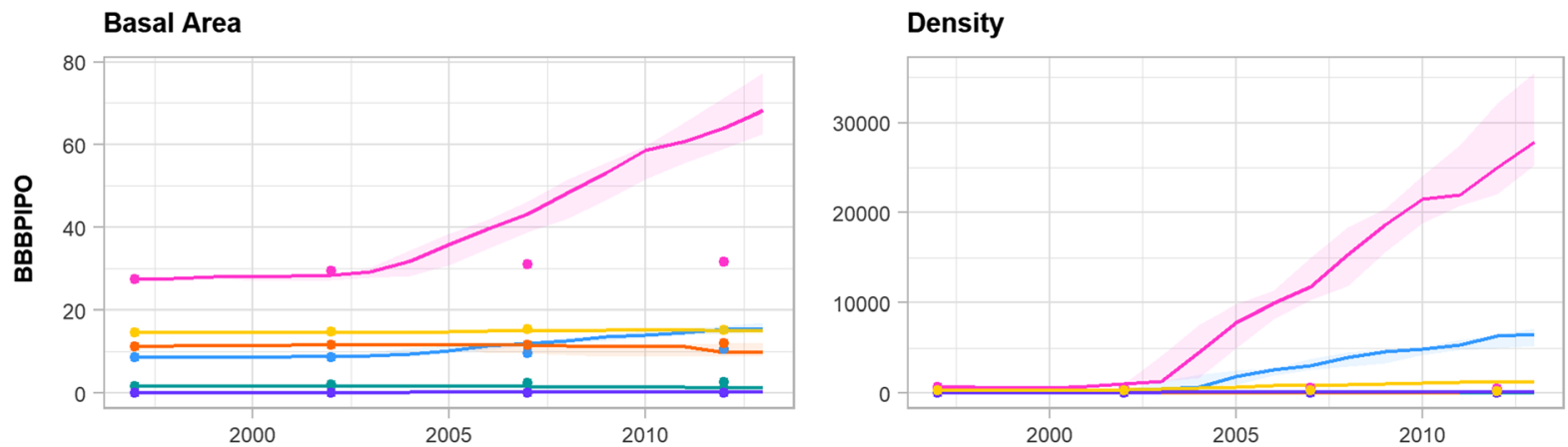

Species
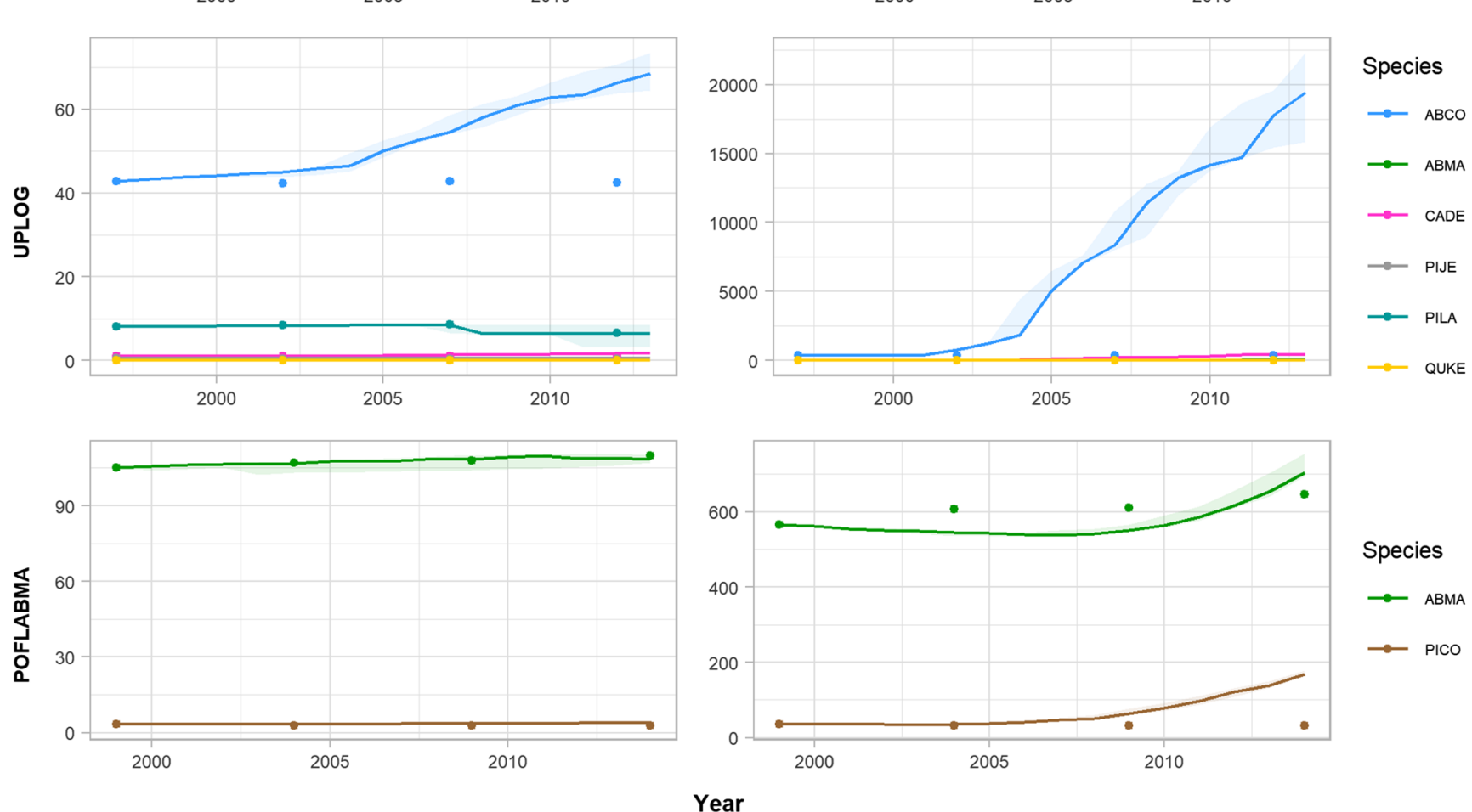

Species

$\rightarrow$ ABMA

$\because$ PICO

Fig. 10 Comparison of modeled and historical basal area (left column) and density (right column) across three plots: BBBPIPO (first row), UPLOG (middle row), and POFLABMA (bottom row). The model was replicated 20 times with the median graphed a solid line, and the shading depicts a $95 \%$ confidence interval. Dots represent total basal area or

density of observed field data in particular year. ABCO, A. concolor; ABMA, A. magnifica; CADE, C. decurrens; PICO, P. contorta; PIJE, P. jeffreyi; PIMO, P. monticola; PIPO, P. ponderosa; QUCH, Q. chrysolepis; QUKE, Q. kellogii 


\section{Appendix 5. Additional graphs and tables of initial conditions and changes in density and basal area}

Fig. 11 Initial conditions for the seven sites. Initial tree density vs. initial basal area, initial basal area vs. elevation, and initial tree density vs. elevation. In the latter case, the relationship is not quite significant $(\mathrm{p}=0.14)$ but the adjusted $R^{2}=0.25$
Fig. 12 Percent change in tree density averaged over 10 runs vs. initial tree density (left) or elevation (right) for the control scenario (top graphs) or climate change scenarios (bottom). In the bottom graphs, red, MIROC ("hot-dry"); blue, CNRM ("warm-wet"); and green, CCSM ("moderatewarm")
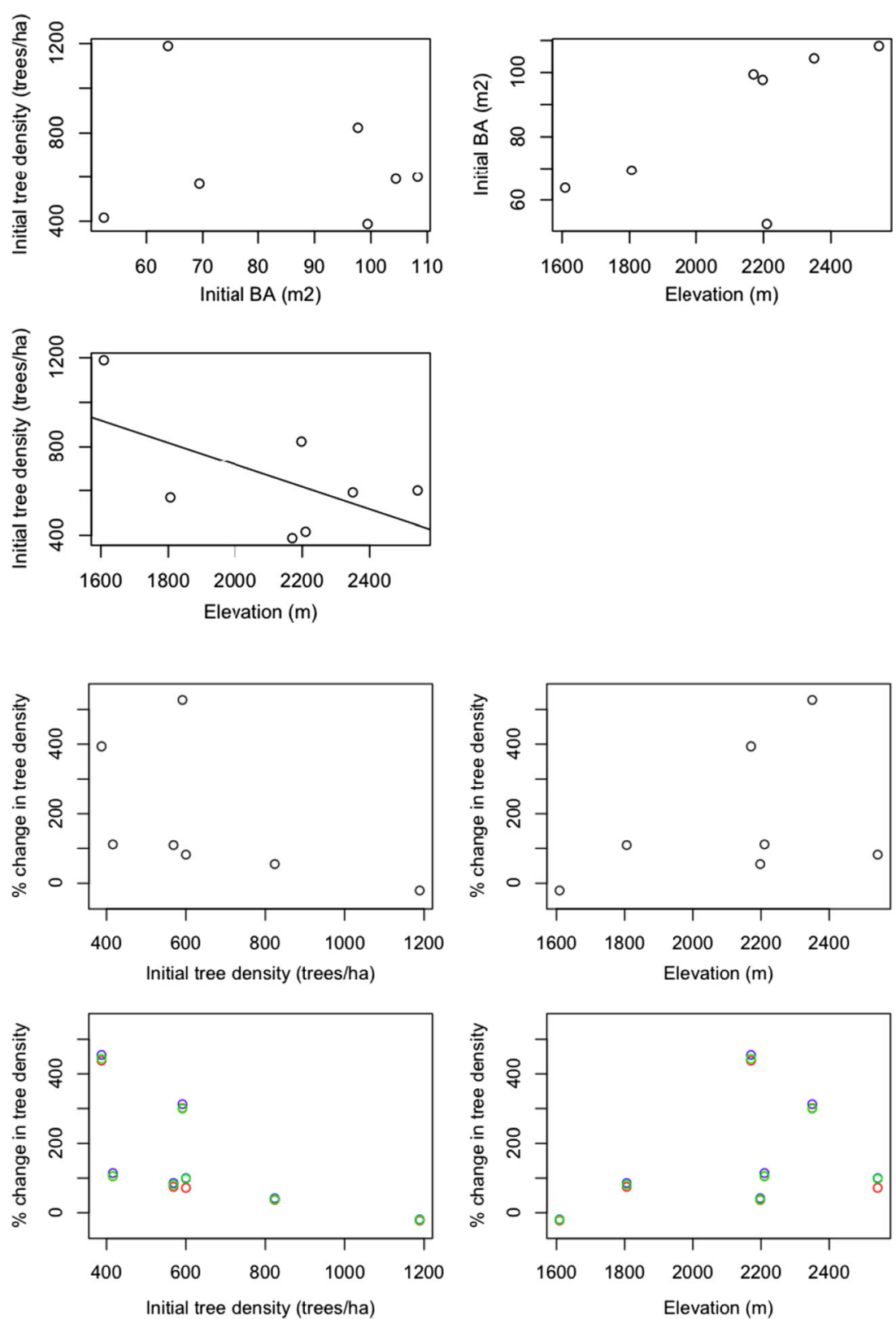
Fig. 13 Percent change in the basal area averaged over 10 runs vs. initial basal area (left) or elevation (right) for the control scenario (top graphs) or climate change scenarios (bottom). In the bottom graphs, red, MIROC ("hot-dry"); blue, CNRM ("warm-wet"); and green, CCSM ("moderate-warm")
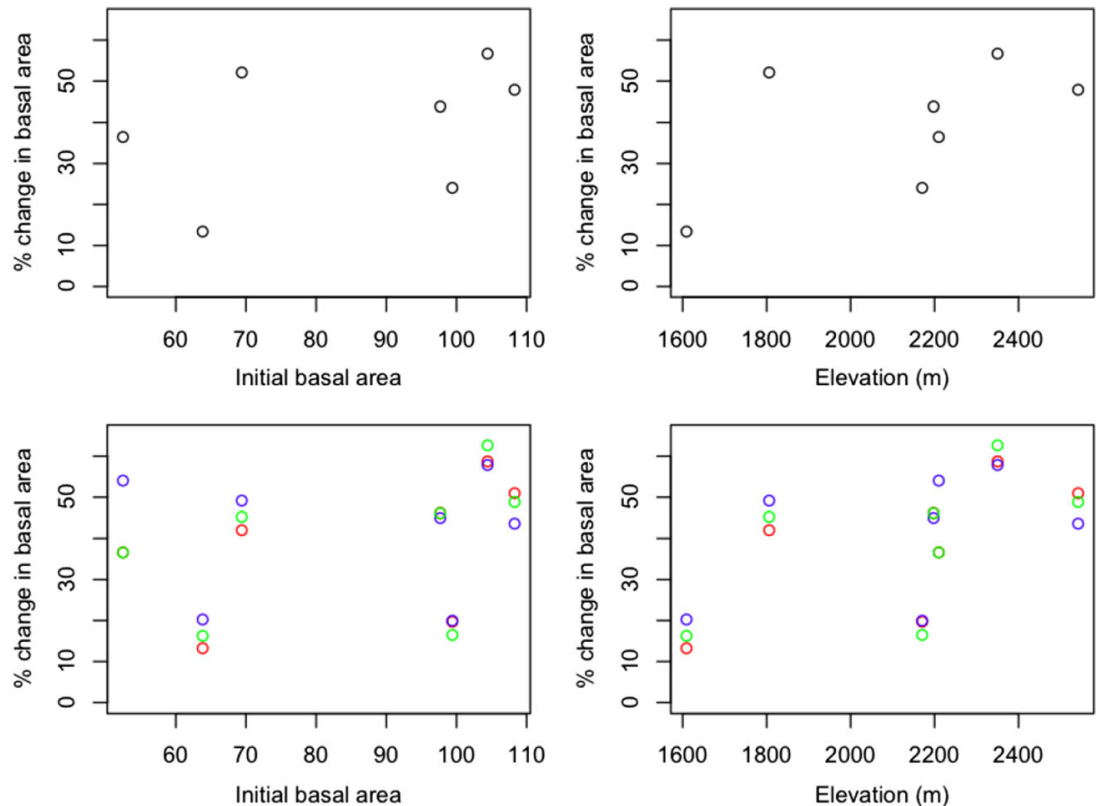

Table. 7 Percent change of basal area and density for control and future climate sequences in 3 plots for total trees and by each species over 93 timesteps from 2006 to 2099, averaged over 10 runs. MIROC "hot-dry",
CNRM "warm-wet", CCSM "moderate-warm". Plots are listed from lowest to highest elevation. ABCO, A. concolor; ABMA, A. magnifica; CADE, C. decurrens; PIJE, P. jeffreyi; PIPO, P. ponderosa; QUKE, Q. kellogii

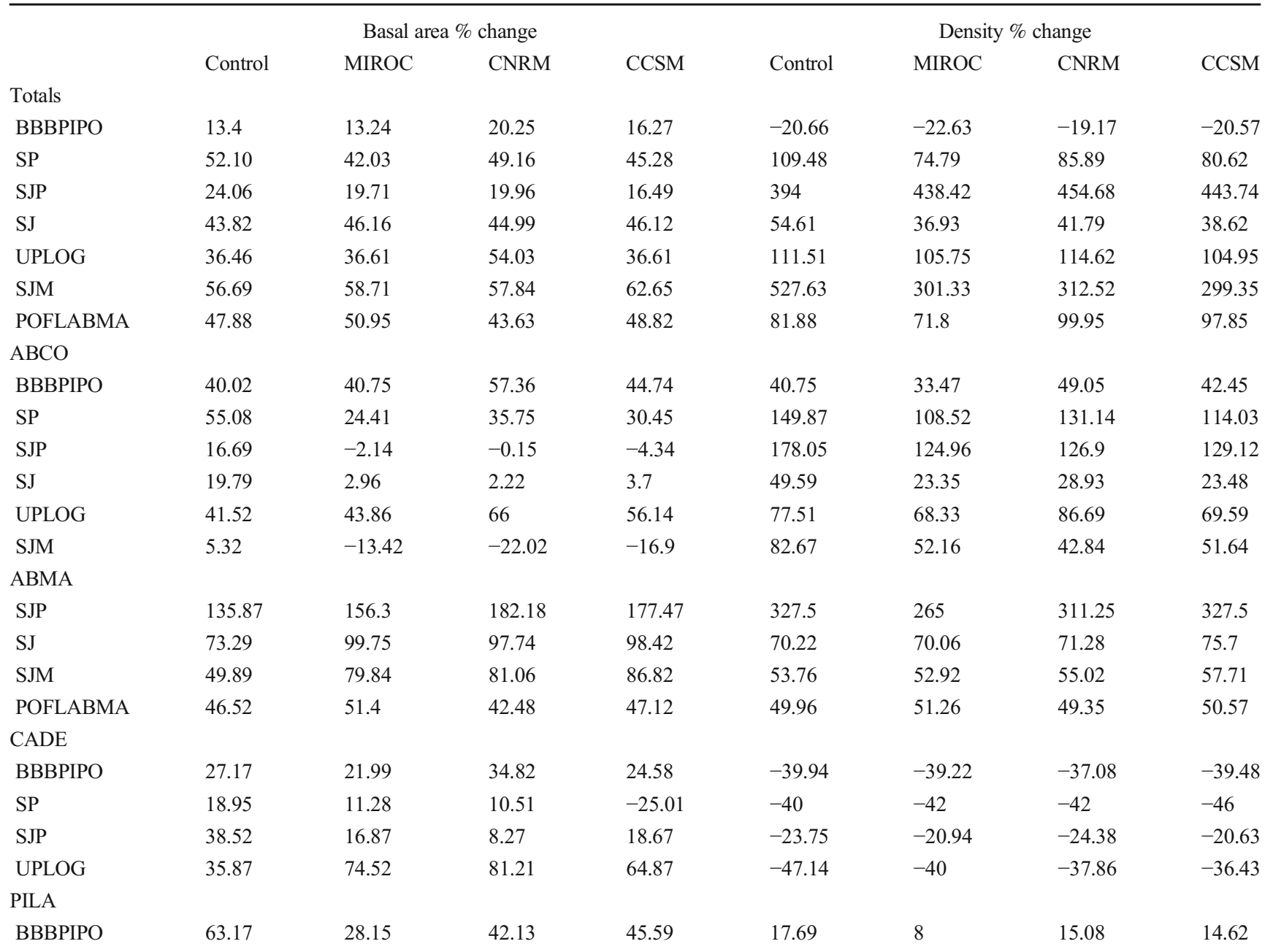


Table. 7 (continued)

\begin{tabular}{|c|c|c|c|c|c|c|c|c|}
\hline SP & 90.44 & 84.42 & 88.04 & 77.09 & 340 & 279.41 & 321.67 & 294.26 \\
\hline SJP & -29.8 & -11.36 & -27.61 & -21.76 & 785.71 & 567.14 & 620 & 625.71 \\
\hline SJ & 213.11 & 176.25 & 241.47 & 257 & 55.71 & 45.71 & 95.71 & 94.29 \\
\hline UPLOG & -4.61 & -28.93 & -25.58 & -10.39 & 349.29 & 275 & 266.79 & 323.57 \\
\hline \multicolumn{9}{|l|}{ PIPO } \\
\hline BBBPIPO & -28.41 & -44.01 & -30.71 & -20.42 & 177.74 & 129.03 & 171.61 & 164.52 \\
\hline SP & 52.92 & -7.55 & -12.33 & -1.76 & 107.15 & 32.36 & 36.02 & 45.77 \\
\hline SJP & 5.75 & 20.04 & -23.31 & -14.85 & 231.43 & 180 & 197.14 & 168.57 \\
\hline \multicolumn{9}{|l|}{ PIJE } \\
\hline SJP & 77.98 & 172.06 & 189.44 & 171.475 & 2430.67 & 3366.33 & 3494.67 & 3362 \\
\hline SJ & -15.72 & 161.7 & 162.25 & 91.75 & -57.5 & 132.5 & 135 & 57.5 \\
\hline UPLOG & 241.81 & 340.49 & 223.03 & 228.47 & 349.29 & 275 & 266.79 & 323.57 \\
\hline \multicolumn{9}{|l|}{ QUKE } \\
\hline BBBPIPO & -2.33 & 23.16 & 7.65 & 8.53 & -35.94 & -34.53 & -39.19 & -35.76 \\
\hline SP & 12.4 & 152.75 & 172.17 & 153.37 & -35.6 & -18.4 & -19.5 & -16.1 \\
\hline UPLOG & -20.29 & 396.06 & 316.11 & 320.85 & -85 & -35 & -40 & -40 \\
\hline
\end{tabular}

Overall mean BA

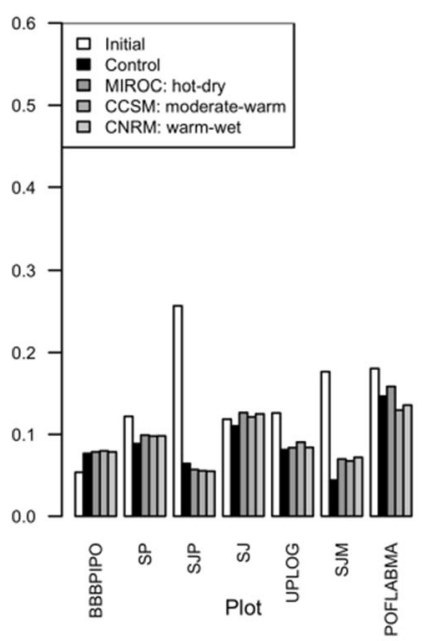

P.lambertiana mean BA

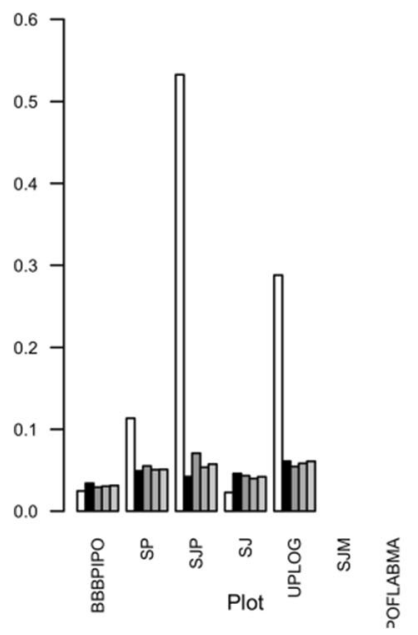

A.concolor mean BA

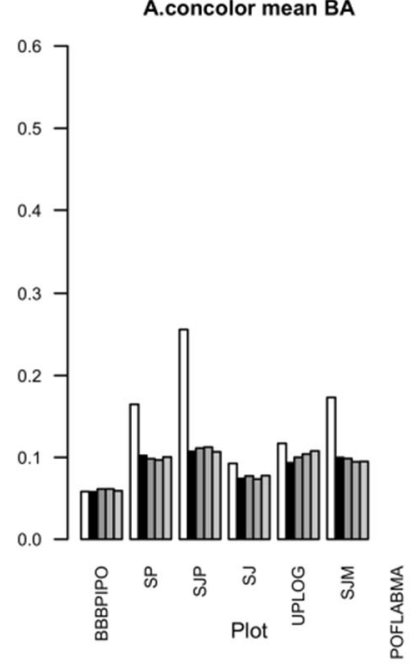

P.ponderosa mean BA

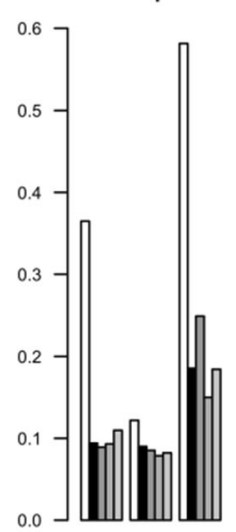

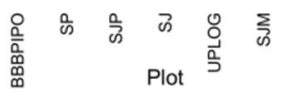

A.magnifica mean BA

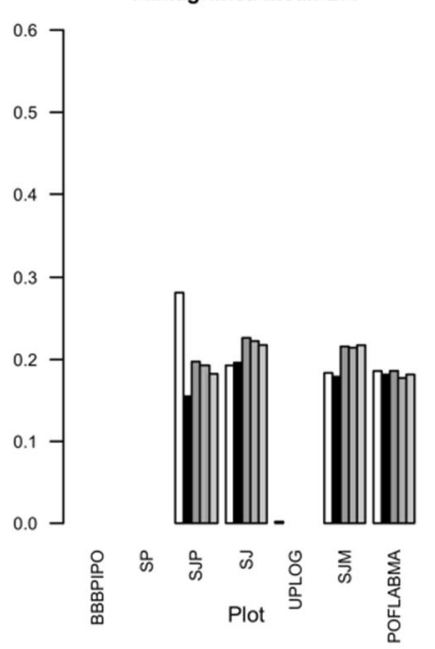

P.jeffreyi mean BA

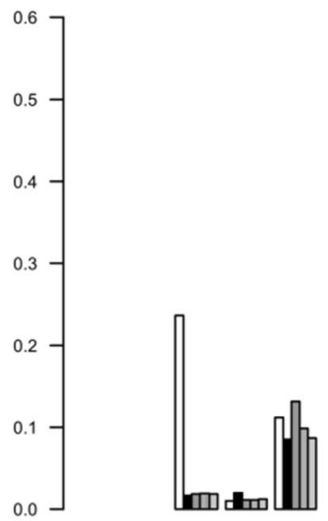

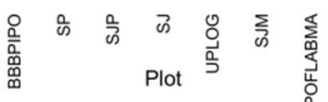

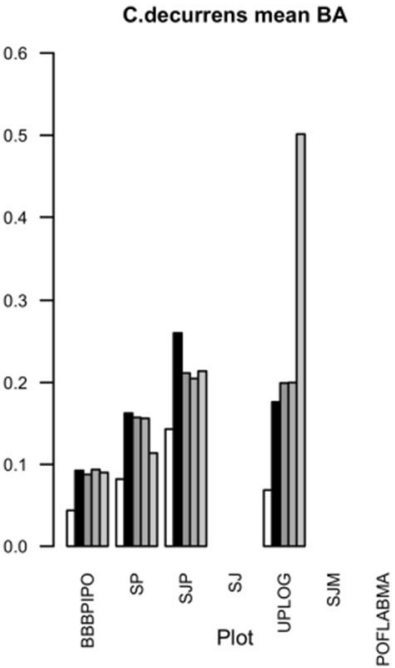

Q.kelloggii mean BA

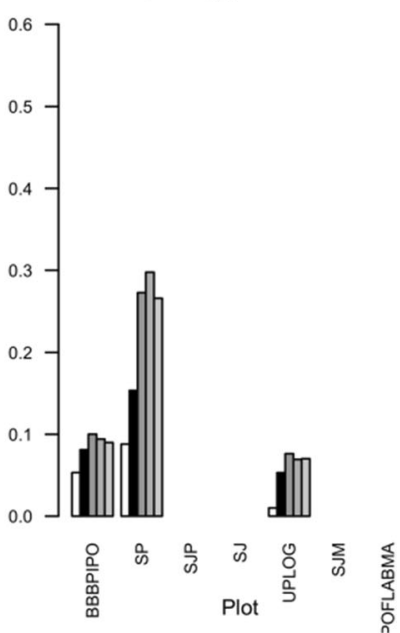

Fig. 14 Average basal area (BA) per tree in $\mathrm{m}^{2}$ initially (white) and at end of the century in control (black) and climate change (gray) scenarios overall and by species. A basal area of $0.1 \mathrm{~m}^{2}$ corresponds to a DBH of $35.6 \mathrm{~cm}$, a basal area of $0.3 \mathrm{~m}^{2}$ to a DBH of $61.8 \mathrm{~cm}$ 
Acknowledgements Thank you to Dr. Adrian Das and Dr. Nathan Stephenson of the US Geological Survey for sharing the datasets that were used to parameterize this model. Dr Sam Davis, a former Moran lab postdoc, developed the allometric equations and began the process of updating SORTIE-ND behaviors. Thanks also to Carmen Tubbesing, Dean $\mathrm{Wu}$, Dr Mengjun Shu, and Dr Jeffrey Lauder for their comments on the manuscript.

Funding This work was funded by UC Merced and NSF award \#1838425.

Data availability Seedling and adult tree data used to parameterize the model are available on www.sciencebase.gov, as reported in Moran et al. (2019) ("Seedling and tree data from Sequoia National Park and Yosemite National Park" https://www.sciencebase.gov/catalog/item/ 5d114632e4b0941bde55077e). Seed data are not publicly available, as they are being used by for ongoing analyses, but are available upon reasonable request from corresponding author. Climate projections were obtained from the California Climate Commons (http://climate. calcommons.org/bcm).

Code availability The parameterized model behaviors will be made available on the SORTIE-ND website upon publication of this manuscript http://sortie-nd.org/index.html. New behaviors currently under review by SORTIE-ND team include "ClimateSeedlingHeightGrowth", "ClimateSeedlingHeightSurvival", "ClimateNCIGrowth", and "ClimateNCIMoratality". Model outputs and the code for making the figures are available through GitHub https://github.com/nrvannest/ SortieForTheSierra. Tree allometry relationships were calculated from FIA data, using the method developed in the package MakeMyForests https://github.com/davis-research/MakeMyForests.

\section{Declarations}

Ethics approval The authors declare that they follow the rules of good scientific practice.

Consent for publication All authors gave their informed consent to this publication and its content.

Conflict of interest The authors declare no competing interests.

Open Access This article is licensed under a Creative Commons Attribution 4.0 International License, which permits use, sharing, adaptation, distribution and reproduction in any medium or format, as long as you give appropriate credit to the original author(s) and the source, provide a link to the Creative Commons licence, and indicate if changes were made. The images or other third party material in this article are included in the article's Creative Commons licence, unless indicated otherwise in a credit line to the material. If material is not included in the article's Creative Commons licence and your intended use is not permitted by statutory regulation or exceeds the permitted use, you will need to obtain permission directly from the copyright holder. To view a copy of this licence, visit http://creativecommons.org/licenses/by/4.0/.

\section{References}

Aitken SN, Whitlock MC (2013) Assisted gene flow to facilitate local adaptation to climate change. Annu Rev Ecol Evol Syst 44:367388. https://doi.org/10.1146/annurev-ecolsys-110512-135747

Allen CD, Macalady AK, Chenchouni H et al (2010) A global overview of drought and heat-induced tree mortality reveals emerging climate change risks for forests. For Ecol Manag 259:660-684. https://doi. org/10.1016/j.foreco.2009.09.001

Ameztegui A, Cabon A, De Cáceres M, Coll L (2017) Managing stand density to enhance the adaptability of Scots pine stands to climate change: a modelling approach. Ecol Model 356:141-150. https:// doi.org/10.1016/j.ecolmodel.2017.04.006

Aubry-Kientz M, Moran EV (2017) Climate impacts on tree growth in the Sierra Nevada. Forests 8:414

Barbour MG, Berg NH, Kittel TGF, Kunz ME (1991) Snowpack and the distribution of a major vegetation ecotone in the Sierra Nevada of California. J Biogeogr 18:141. https://doi.org/10.2307/2845288

Battles JJ, Robards T, Das A et al (2008) Climate change impacts on forest growth and tree mortality: a data-driven modeling study in the mixed-conifer forest of the Sierra Nevada, California. Clim Chang 87:193-213. https://doi.org/10.1007/s10584-007-9358-9

Beaty RM, Taylor AH (2007) Fire disturbance and forest structure in oldgrowth mixed conifer forests in the northern Sierra Nevada, California. J Veg Sci 18:879-890. https://doi.org/10.1111/j.16541103.2007.tb02604.x

Bonan GB (2008) Forests and climate change: forcings, feedbacks, and the climate benefits of forests. Science 320:1444-1449. https://doi. org/10.1126/science.1155121

Bose AK, Harvey BD, Coates KD et al (2015) Modelling stand development after partial harvesting in boreal mixedwoods of eastern Canada. Ecol Model 300:123-136. https://doi.org/10.1016/j. ecolmodel.2015.01.002

Burns RM, Honkala BH (1990) Silvics of North America. USDA Forest Service, Washington

CDWR (2019) Water year 2020 begins with robust reservoir storage. http://water.ca.gov/News/News-Releases/2019/October-19/WaterYear-2020-Begins-with-Robust-Reservoir-Storage. Accessed 9 Oct 2019

Charney ND, Babst F, Poulter B et al (2016) Observed forest sensitivity to climate implies large changes in 21st century North American forest growth. Ecol Lett 19:1119-1128. https://doi.org/10.1111/ ele. 12650

Clark JS, Andrus R, Aubry-Kientz M et al (2021) Continent-wide tree fecundity driven by indirect climate effects. Nat Commun 12:1242. https://doi.org/10.1038/s41467-020-20836-3

Clark JS, Beckage B, Camil P et al (1999) Interpreting recruitment limitation in forests. Am J Bot 86:1-16

Collins BM, Everett RG, Stephens SL (2011) Impacts of fire exclusion and recent managed fire on forest structure in old growth Sierra Nevada mixed-conifer forests. Ecosphere 2:1-14. https://doi.org/ 10.1890/ES11-00026.1

Dolanc CR, Safford HD, Dobrowski SZ, Thorne JH (2014a) Twentieth century shifts in abundance and composition of vegetation types of the Sierra Nevada, CA, US. Appl Veg Sci 17:442-455. https://doi. org/10.1111/avsc. 12079

Dolanc CR, Safford HD, Thorne JH, Dobrowski SZ (2014b) Changing forest structure across the landscape of the Sierra Nevada, CA, USA, 
since the 1930s. Ecosphere 5:art101. https://doi.org/10.1890/ES1400103.1

Earles JM, North MP, Hurteau MD (2014) Wildfire and drought dynamics destabilize carbon stores of fire-suppressed forests. Ecol Appl 24: 732-740

Easterday K, McIntyre P, Kelly M (2018) Land ownership and 20th century changes to forest structure in California. For Ecol Manag 422:137-146. https://doi.org/10.1016/j.foreco.2018.04.012

Fettig CJ, Mortenson LA, Bulaon BM, Foulk PB (2019) Tree mortality following drought in the central and southern Sierra Nevada, California, U.S. For Ecol Manag 432:164-178. https://doi.org/10. 1016/j.foreco.2018.09.006

Flint LE, Flint AL, Thorne JH, Boynton R (2013) Fine-scale hydrologic modeling for regional landscape applications: the California Basin Characterization Model development and performance. Ecol Process 2:1-21. https://doi.org/10.1186/2192-1709-2-25

Gallego Zamorano J, Hokkanen T, Lehikoinen A (2018) Climate-driven synchrony in seed production of masting deciduous and conifer tree species. J Plant Ecol 11:180-188. https://doi.org/10.1093/jpe/ rtw117

Goulden ML, Bales RC (2014) Mountain runoff vulnerability to increased evapotranspiration with vegetation expansion. Proc Natl Acad Sci 111:14071-14075. https://doi.org/10.1073/pnas. 1319316111

Grossiord C, Gessler A, Granier A et al (2014) Impact of interspecific interactions on the soil water uptake depth in a young temperate mixed species plantation. J Hydrol 519(Part D):3511-3519. https://doi.org/10.1016/j.jhydrol.2014.11.011

Haller JR (1959) Factors affecting the distribution of Ponderosa and Jeffrey pines in California. Madrono 15:65-71

IPCC (2013) Climate change 2013: The physical science basis. Contribution of Working Group I to the Fifth Assessment Report of the Intergovernmental Panel on Climate Change. Cambridge University Press, Cambridge and New York

Keeley J, Syphard A (2016) Climate change and future fire regimes: examples from California. Geosciences 6:37. https://doi.org/10. 3390/geosciences6030037

Koenig WD, Knops JMH, Carmen WJ, Pearse IS (2015) What drives masting? The phenological synchrony hypothesis. Ecology 96:184 192. https://doi.org/10.1890/14-0819.1

Krofcheck DJ, Hurteau MD, Scheller RM, Loudermilk EL (2017) Restoring surface fire stabilizes forest carbon under extreme fire weather in the Sierra Nevada. Ecosphere 8:e01663. https://doi.org/ $10.1002 /$ ecs2.1663

Lenihan JM, Drapek R, Bachelet D, Neilson RP (2003) Climate change effects on vegetation distribution, carbon, and fire in California. Ecol Appl 13:1667-1681

Liang S, Hurteau MD, Westerling AL (2017) Response of Sierra Nevada forests to projected climate-wildfire interactions. Glob Chang Biol 23:2016-2030. https://doi.org/10.1111/gcb.13544

Martin PH, Canham CD, Kobe RK (2010) Divergence from the growthsurvival trade-off and extreme high growth rates drive patterns of exotic tree invasions in closed-canopy forests: growth and survivorship in exotic tree invasions. J Ecol 98:778-789. https://doi.org/10. 1111/j.1365-2745.2010.01666.x

McIntyre PJ, Thorne JH, Dolanc CR et al (2015) Twentieth-century shifts in forest structure in California: denser forests, smaller trees, and increased dominance of oaks. Proc Natl Acad Sci U S A 112: 1458-1463. https://doi.org/10.1073/pnas.1410186112

Moran EV, Das AJ, Keeley J, Stephenson NL (2019) Negative impacts of summer heat on Sierra Nevada tree seedlings. Ecosphere 10:e02776. https://doi.org/10.1002/ecs2.2776
Murray KD, Lohman RB (2018) Short-lived pause in Central California subsidence after heavy winter precipitation of 2017. Sci Adv 4: eaar8144. https://doi.org/10.1126/sciadv.aar8144

Oren R, Ellsworth DS, Johnsen KH et al (2001) Soil fertility limits carbon sequestration by forest ecosystems in a $\mathrm{CO} 2$ enriched atmosphere. Nature 411:469-472

Pacala SW, Canham CD, Saponara J et al (1996) Forest models defined by field measurements: estimation, error analysis and dynamics. Ecol Monogr 66:1. https://doi.org/10.2307/2963479

$\mathrm{R}$ core team (2017) R: a language and environment for statistical computing. R Foundation for Statistical Computing, Vienna

Reidmiller DR, Avery CW, Easterling DR, et al (eds) (2018) Impacts, risks, and adaptation in the United States: Fourth National Climate Assessment, Volume II: Report-in-Brief

Rice KJ, Emery NC (2003) Managing microevolution: restoration in the face of global change. Front Ecol Environ 1:469-478

Roelfsema M, van Soest HL, Harmsen M et al (2020) Taking stock of national climate policies to evaluate implementation of the Paris Agreement. Nat Commun 11:2096. https://doi.org/10.1038/ s41467-020-15414-6

Rogelj J, den Elzen M, Höhne N et al (2016) Paris Agreement climate proposals need a boost to keep warming well below $2{ }^{\circ} \mathrm{C}$. Nature 534:631-639. https://doi.org/10.1038/nature18307

Swain DL, Tsiang M, Haugen M et al (2014) The extraordinary California drought of 2013/2014 : character, context, and the role of climate change. Bull Am Meteorol Soc 95:3-7

Tomback DF, Achuff P (2010) Blister rust and western forest biodiversity: ecology, values and outlook for white pines. For Pathol 40: 186-225. https://doi.org/10.1111/j.1439-0329.2010.00655.x

Uriarte M, Canham CD, Thompson J et al (2009) Natural disturbance and human land use as determinants of tropical forest dynamics: results from a forest simulator. Ecol Monogr 79:423-443. https://doi.org/ 10.1890/08-0707.1

van Mantgem PJ, Stephenson NL, Byrne JC et al (2009) Widespread increase of tree mortality rates in the western United States. Science 323:521-524

Wilmking M, Maaten-Theunissen M, Maaten E et al (2020) Global assessment of relationships between climate and tree growth. Glob Chang Biol 26:3212-3220. https://doi.org/10.1111/gcb.15057

Bugmann HKM (1996) A simplified forest model to study species composition along climate gradients. Ecology. 77(7): 2055-2074

Bugmann HKM (2001) A review of forest gap models. Climatic Change. 51: 259-305. 10.1023/A:1012525626267

Kienast F (1991) Simulated effects of increasing atmospheric $\mathrm{CO}_{2}$ and changing climate on the successional characteristics of Alpine forest ecosystems. Landscape Ecology. 5: 225-238. 10.1007/BF00141437

Prentice IC, Sykes MT, Cramer W (1993) A simulation model for the transient effects of climate change on forest landscapes. Ecological Modelling. 65(1-2): 51-70. 10.1016/0304-3800(93)90126-D

Purves DW, Lichstein JW, Strigul N, et al. (2008) Predicting and understanding forest dynamics using a simple tractable model. Proceedings of the National Academy of Sciences. 105(44): 17018-17022. https://doi.org/10.1073/pnas.0807754105

Clark JS, Silman M, Kern R, Macklin E, Lambers J HR (1999)Seed dispersal near and far: patterns across temperate andtropical forests. Ecology, 80, 1475-1494

Publisher's note Springer Nature remains neutral with regard to jurisdictional claims in published maps and institutional affiliations. 